\title{
Atmosphere Feedbacks during ENSO in a Coupled GCM with a Modified Atmospheric Convection Scheme
}

\author{
Eric Guilyardi, ${ }^{*}$ Pascale Braconnot, ${ }^{+}$Fei-Fei Jin, ${ }^{\#}$ SeOn TAE Kim,

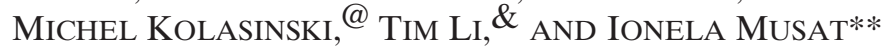 \\ * LOCEAN/IPSL (CNRS/UPMC/IRD), Paris, France, and NCAS Climate, Walker Institute, University of Reading, \\ Reading, United Kingdom \\ + LSCE/IPSL (CEA/CNRS), Gif-sur-Yvette, France \\ \# Department of Meteorology, University of Hawaii at Manoa, Honolulu, Hawaii \\ @ LOCEAN/IPSL (CNRS/UPMC/IRD), Paris, France \\ \& IPRC and Department of Meteorology, University of Hawaii at Manoa, Honolulu, Hawaii \\ ** LMD/IPSL (CNRS), Paris, France
}

(Manuscript received 2 September 2008, in final form 3 June 2009)

\begin{abstract}
The too diverse representation of ENSO in a coupled GCM limits one's ability to describe future change of its properties. Several studies pointed to the key role of atmosphere feedbacks in contributing to this diversity. These feedbacks are analyzed here in two simulations of a coupled GCM that differ only by the parameterization of deep atmospheric convection and the associated clouds. Using the Kerry-Emanuel (KE) scheme in the L'Institut Pierre-Simon Laplace Coupled Model, version 4 (IPSL CM4; KE simulation), ENSO has about the right amplitude, whereas it is almost suppressed when using the Tiedke (TI) scheme. Quantifying both the dynamical Bjerknes feedback and the heat flux feedback in KE, TI, and the corresponding Atmospheric Model Intercomparison Project (AMIP) atmosphere-only simulations, it is shown that the suppression of ENSO in TI is due to a doubling of the damping via heat flux feedback. Because the Bjerknes positive feedback is weak in both simulations, the KE simulation exhibits the right ENSO amplitude owing to an error compensation between a too weak heat flux feedback and a too weak Bjerknes feedback. In TI, the heat flux feedback strength is closer to estimates from observations and reanalysis, leading to ENSO suppression. The shortwave heat flux and, to a lesser extent, the latent heat flux feedbacks are the dominant contributors to the change between TI and KE. The shortwave heat flux feedback differences are traced back to a modified distribution of the large-scale regimes of deep convection (negative feedback) and subsidence (positive feedback) in the east Pacific. These are further associated with the model systematic errors. It is argued that a systematic and detailed evaluation of atmosphere feedbacks during ENSO is a necessary step to fully understand its simulation in coupled GCMs.
\end{abstract}

\section{Introduction}

ENSO is the strongest mode of interannual climate variability with significant impacts both in the tropics and at higher latitudes. Because it involves many different feedbacks (Wang and Picaut 2004), understanding and predicting both ENSO occurrence and amplitude is still a scientific challenge (McPhaden et al. 2006). For instance, the Intergovernmental Panel on Climate Change Fourth Assessment Report (IPCC AR4) sce-

Corresponding author address: Eric Guilyardi, LOCEAN/IPSL, UPMC, Case 100, 4 Place Jussieu, F-75252, Paris CEDEX, France. E-mail: eric.guilyardi@locean-ipsl.upmc.fr narios do not show any clear evolution of ENSO properties in a warmer climate (Meehl et al. 2007; Guilyardi et al. 2009). Part of this uncertainty is due to model systematic errors. Indeed, and even though much progress has been achieved in the last decade, coupled ocean-atmosphere GCMs still have errors in reproducing the observed characteristics of El Niño events (AchutaRao and Sperber 2006; van Oldenborgh et al. 2005; Guilyardi 2006; Capotondi et al. 2006). Improving the next generation of state-of-the-art IPCC-class models is therefore a prerequisite to reliable projections of the likely evolution of ENSO in the future.

Several studies have pointed out the dominant role of the atmospheric component in setting ENSO 
characteristics in state-of-the-art models (Schneider 2002; Guilyardi et al. 2004; Kim et al. 2008; Neale et al. 2008; Wu et al. 2007; Sun et al. 2008). It is nevertheless unclear why, and further analysis of the ocean-atmosphere feedbacks is a key to understanding and eventually correcting ENSO biases. Even though such an analysis is complicated by the fact that the origins of the biases are usually model dependent, one can nevertheless derive diagnostics to assess in detail the role of atmosphere processes during ENSO and compare them with observations, when available. Together with the estimation of ocean processes (Fedorov 2007; Dewitte et al. 2007; Jin et al. 2006), one should then be able to fully understand the specific ENSO characteristics of any particular coupled GCM (Guilyardi et al. 2009).

The atmospheric feedbacks during ENSO are of two types (Battisti and Hirst 1989; Jin et al. 2006; Lin 2007). First, the dynamical feedback ( $\mu$, or coupling strength), also called Bjerknes feedback (Bjerknes 1969; Neelin and Djikstra 1995), is the intensity of the wind stress response to a given near-equatorial/tropical sea surface temperature (SST) anomaly; it is a positive feedback and maintains a large-scale east-west asymmetry across the equatorial Pacific. Second, the heat flux feedback $(\alpha)$ usually represents a damping of SST anomalies by both radiative and turbulent heat fluxes (Waliser et al. 1994; Jin et al. 2006). At interannual time scales, the two dominant terms in the tropical Pacific are the shortwave heat flux (SHF) feedback $\left(\alpha_{\mathrm{SW}}\right)$ (see Bony et al. 1997) and the latent heat flux (LHF) feedback $\left(\alpha_{\mathrm{LH}}\right)$. Indeed, in this region, the longwave heat flux is mostly related to the SST and changes little and the sensible heat flux is weak as the near-surface air temperature is close to the SST. The mean annual $\alpha$ is a negative feedback over most of the tropics, although its components can in time become positive. For instance, $\alpha_{\mathrm{SW}}$ is negative over the warm pool where deep convection prevails (higher SST lead to increased deep convection, hence increased cloudiness and reduced shortwave heat flux, Ramanathan and Collins 1991), but positive over the cool tongue where higher SST reduce the stability of the boundary layer and thus the marine stratiform clouds amount (Wallace et al. 1989; Klein and Hartmann 1993; Norris and Leovy 1994; $\mathrm{Li}$ and Philander 1996; Li 1997b). The SST-SHF (LHF) relation described by these feedbacks encompasses both local (i.e., pointwise) thermodynamical mechanisms and remote processes (Stephens 2005). For instance, several studies have pointed to the key role of the large-scale atmospheric circulation in these feedbacks and, in particular, the vertical motions (Fu et al. 1994; Lau et al. 1997; Bony et al. 1997, 2004). Heat flux feedbacks have also been shown to have a key role in the tropical Atlantic Ocean, explaining a large fraction of model errors and diversity (Frankignoul et al. 2004).

The high sensitivity of the modeled atmosphere to the parameterization of deep convection has been documented by a number of studies (e.g., Zhang and McFarlane 1995; Hourdin et al. 2006; Braconnot et al. 2007, hereafter B07). The parameterization of deep convection and the associated clouds acts to mimic the way the atmosphere is destabilized by surface heating, how its properties are mixed vertically, and indirectly what surface fluxes are generated. In the real atmosphere, individual convective events can happen at very small horizontal scales (several hundred meters at most) and involve rapidly ascending and descending motions and complex thermodynamics (Emanuel 1994). These events then become organized into clusters at larger scale. The challenge of the different convection schemes devised over the years has been to represent the mean effect of these convective events over grid cells of several hundreds of kilometers in size.

The deep convection parameterization, which interacts with the clouds scheme, the boundary layer, and the dynamics, is of central importance in modeling of the tropical atmosphere. Indeed, deep convection is the primary heat source driving the large-scale circulation, affects wave disturbances through the release of latent heat, and drives the vertical redistribution of heat, moisture, and momentum. The representation of deep convection is therefore central in defining both the dynamical and the heat flux atmosphere feedbacks during ENSO. Several recent studies have documented the impact of a modified convection scheme on ENSO in coupled GCMs. Kim et al. (2008) and Neale et al. (2008) have shown that including convective momentum transport (CMT) redistributes momentum vertically toward the surface during ENSO, shifting mean and interannual structures back toward the east. In the model used by Kim et al., the ENSO amplitude strongly increases when the CMT is added, owing to a $50 \%$ increase of the Bjerknes feedback $\mu$. In Neale et al. (2008) and $\mathrm{Wu}$ et al. (2007), adding the CMT leads to striking improvements in ENSO simulation and alleviates the strong 2-yr period ENSO in the control simulation. Neale et al. (2008) argue that the improvements come from a stronger role of intraseasonal variability and a redistribution of zonal momentum that leads both to increased $\mu$ and $\alpha$. Even with the same atmospheric physics, deep convection can significantly affect the evolution and termination of ENSO in the east Pacific via local feedbacks (Zhang and McPhaden 2008; Lengaigne and Vecchi 2009).

Hence, the impacts of the atmosphere deep convection on ENSO can be due to changes in the background 
state, changes in the intraseasonal variability, and change in local thermodynamic feedbacks-all three aspects playing a key role in ENSO. For instance, adding the CMT acts to reduce wind stress easterly biases, which were shown to be related to too weak ENSO amplitude (Guilyardi 2006). The change in the simulation of intraseasonal variability (Neale et al. 2008; Wu et al. 2007) can lead to changes in the triggering and amplification of ENSO as shown by Lengaigne et al. (2004).

Here we analyze the different atmospheric ENSO feedbacks in two simulations of the L'Institut PierreSimon Laplace (IPSL) Coupled Model, version 4 -(CM4) model that differ by the deep convection and the associated cloud scheme used: the standard IPCC version with the Kerry-Emanuel (KE) scheme and the Tiedke (TI) scheme, the rest of the atmosphere and the ocean being exactly the same. The Atmospheric Model Intercomparison Project (AMIP) atmosphere-only simulations were described by Hourdin et al. (2006), and the mean state and seasonal cycle of the coupled simulations were described by B07. The striking feature of these simulations is that, while the control KE simulation does exhibit ENSO with about the right amplitude, ENSO in the TI simulation is almost suppressed (Fig. 1). We show that this suppression is largely due to modified atmospheric feedbacks and investigate the reasons why.

Section 2 describes the model, the KE and TI simulations, and the reference observation used. Section 3 evaluates the ENSO properties of the two simulations, and section 4 investigates the details of the different atmospheric feedbacks and unravels the reasons for ENSO suppression in the TI simulation. Section 5 identifies the model systematic errors responsible for the atmosphere feedback deficiencies. A summary and a discussion are presented in section 6 .

\section{Model and simulations}

\section{a. Model and simulations}

The model used in this study is the IPSL CM4 model (Marti et al. 2009), which couples the Laboratoire de Météorologie Dynamique (LMDz) AGCM (Hourdin et al. 2006) and the Océan Parallélisé (OPA) OGCM (Madec et al. 1998) via the Ocean-Atmosphere-Sea Ice-Soil (OASIS) coupler (Valcke et al. 2000). The standard configuration, used for the IPCC AR4 (Solomon et al. 2007), uses the Kerry-Emanuel convection scheme and the associated cloud scheme in LMDz. A sensitivity simulation using the Tiedke convection scheme and the associated cloud scheme is also made. The KE scheme gives a unique treatment of both deep and shallow convection and has a more complex representation of

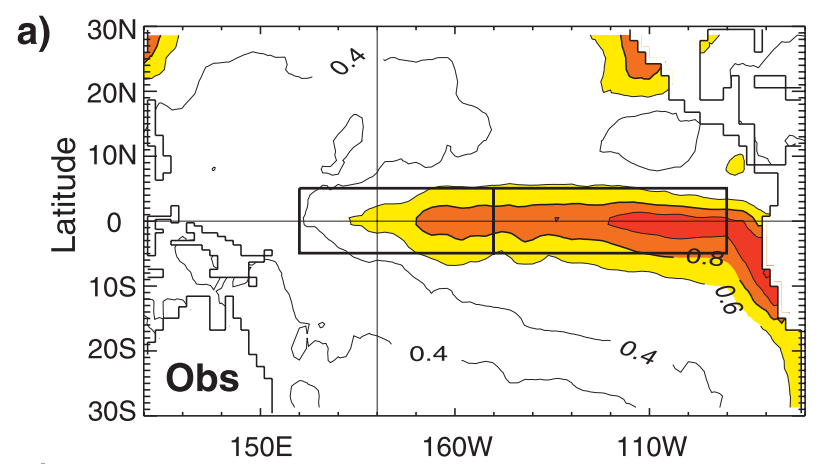

b)

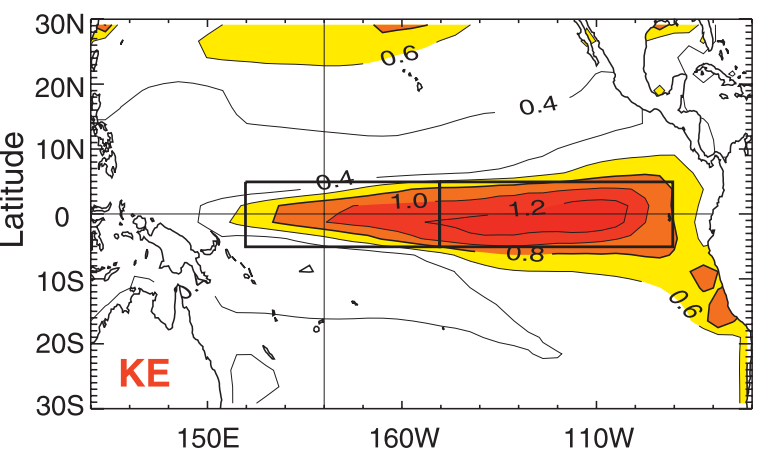

c)

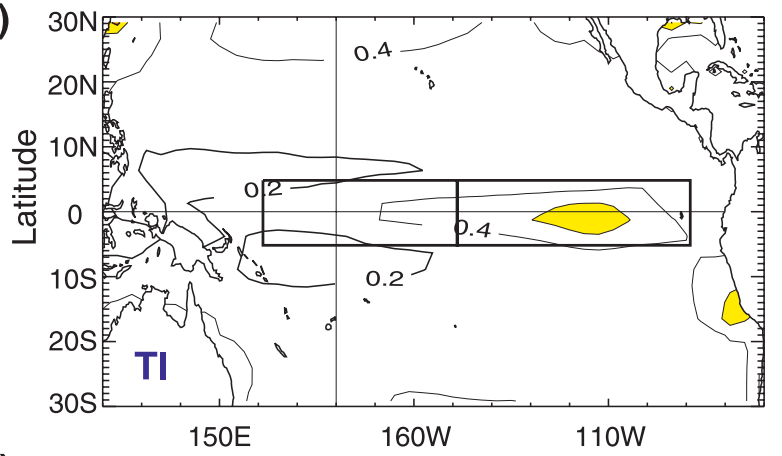

d)

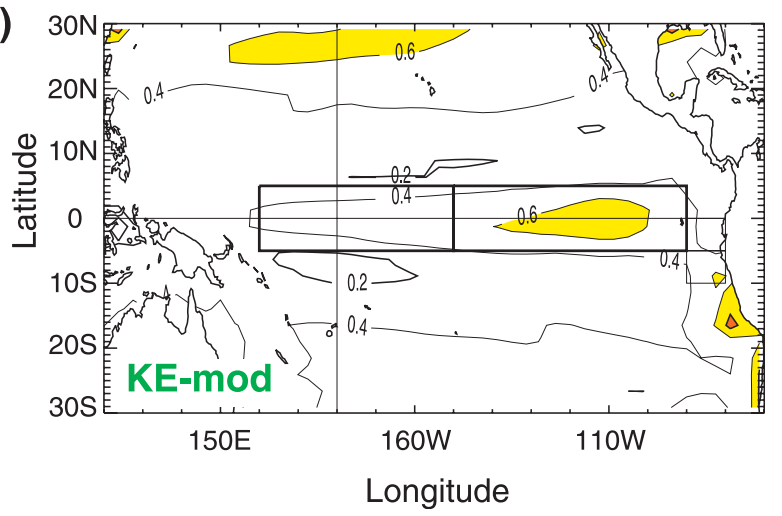

FIG. 1. Monthly SST anomaly standard deviation for (a) 1900-99 HadISST1.1 and 100 years of IPSL CM4 with the (b) KerryEmanuel convection scheme, (c) the Tiedke convection scheme, and (d) the KE convection scheme using an interannual SW heat flux correction (KE-mod); see text. Contours every $0.2^{\circ} \mathrm{C}$; Niño-3 (to the east) and Niño-4 (to the west) regions are indicated. 
downdrafts, which helps to limit an otherwise overactive convection, especially over the oceans. The representation of clouds associated with cumulus convection differs between KE and TI. In KE it is coupled to the deep convection scheme by using the prognostic incloud water content and the degree of saturation of the large-scale environment (Bony and Emanuel 2001), whereas in TI an assumed homogenous cloud fraction is a function of the vertically integrated moistening tendency predicted by the Tiedke convection scheme (Hourdin et al. 2006). In TI, the radiative effect of convective clouds is also treated differently. A more complete description of these schemes can be found in Hourdin et al. (2006) (sections 2.3 and 2.4) and B07 (section 2b). The only adjustment made in TI (when compared to KE) affected the radiation scheme [so as to have a balanced top of atmosphere (TOA) heat flux] and the differences seen in TI also existed in a nonadjusted simulation. The AMIP atmosphere-only simulations (AMIP-KE and AMIP-TI) span the 1979-2002 period (which encompass the 1982-83 and 1997-98 El Niño events) and are described in Hourdin et al. The setup, the mean state, and seasonal cycle of the KE and TI simulations, of which 100 years are used here, are described for the tropical Pacific in B07. It is worth noting that distinguishing the detailed relative impacts of both changes (convection scheme versus cumulus cloud scheme) is not possible since the convective scheme change will also modify the latent heating and the vertical distribution of moisture, hence the cumulus cloud properties. Nevertheless, the sensitivity experiments made in AMIP mode by Hourdin et al. suggest that the change of convection scheme has a dominant effect.

\section{b. Validation datasets}

Several datasets are used to evaluate the performance of the model. In all cases, monthly means are used. SSTs are compared to the Met Office's Hadley Center's Sea Ice and SST dataset version 1 (HadISST1) (Rayner et al. 2003) and the Reynolds (1988) dataset used for the National Centers for Environmental Prediction (NCEP) reanalysis. Precipitations are compared to the Climate Prediction Center's Merged Analysis of Precipitation (CMAP) (Xie and Arkin 1997). Wind stress comes from the 40-yr European Centre for Medium-Range Weather Forecasts Re-Analysis (ERA-40) (Uppala et al. 2005), NCEP/Department of Energy Global Reanalysis 2 (NCEP-2) (Kalnay et al. 1996) and a combination of European Remote Sensing Satellite (ERS) and TAO (Menkes et al. 1998). Ocean surface heat fluxes are compared to ERA-40, the International Satellite Cloud Climatology Project (ISCCP) (Zhang et al. 2004) and objectively analyzed air-sea fluxes (OAFlux) (Yu et al.
2007), and cloud cover from ISCCP (Rossow and Schiffer 1991). The three-dimensional structure of the atmosphere is compared to ERA-40 and NCEP-2. In the ocean, two reference-forced OGCMs are used. They are made from the same OGCM [Nucleus for European Modelling of the Ocean (NEMO)-OPA] but at higher resolution $\left(0.5^{\circ}\right.$ instead of $2^{\circ}-0.5^{\circ}$ in KE/TI $)$ and use two sets of Coordinated Ocean and Sea Ice Reference Experiment (CORE) (Griffies et al. 2009) forcing: one based on NCEP-2 and the other on ERA-40 (Barnier et al. 2006; Molines et al. 2006). In the comparison, and whenever possible, two references are used to illustrate the observations/reanalysis uncertainty, keeping in mind that this only provides a lower bound to the uncertainty.

\section{c. Mean state and seasonal cycle in the tropical Pacific}

ENSO is defined as an anomaly to the mean seasonal cycle. It is therefore key to describe this seasonal cycle, especially in coupled models where it can exhibit quite different behaviors in the tropical areas (Covey et al. 2000; Guilyardi 2006; Wu et al. 2008). Moreover, errors in ENSO simulations can often be traced back to errors in the background state, as will be shown in section 5 .

In the tropical Pacific, B07 described significant changes in the seasonal cycle between KE and TI. We detail here the aspects relevant to ENSO mechanisms. Figure 2 presents the mean seasonal cycle at the equator in the Pacific for the zonal wind stress (shading), the SST (contour), and the 3 and $8 \mathrm{~mm} \mathrm{day}^{-1}$ precipitation contours. In the observations and reanalysis (Figs. $2 \mathrm{a}$ and $2 \mathrm{~b}$ ), the trade winds (easterlies) are strong during Northern Hemisphere (NH) summer and autumn and are associated with the upwelling of colder SST in the east Pacific via strong coupling (Bjerknes feedback, $\mu$ ). In $\mathrm{NH}$ spring, the coupled system relaxes, the trade winds weaken, and the SST in the east Pacific warms up. The bulk of the atmospheric deep convection (as delimited by the $3 \mathrm{~mm}$ day ${ }^{-1}$ precipitation contours) stays west of the date line, and the seasonal cycle in the west Pacific is weak.

KE exhibits a quite well-simulated seasonal cycle in the equatorial Pacific (Fig. 2e), especially when compared to other IPCC-class models (Guilyardi 2006). In the east Pacific, the upwelling is timed right (even though it does not last long enough) and the NH spring relaxation is present. In the west Pacific, the annual cycle is weak, like in observations, and the deep convection mostly stays west of the date line. A common bias of many coupled GCMs is that the patterns are shifted westward: the upwelling does not reach the South American coast and the easterlies extend too far into the warm pool, especially during December-February (DJF), when westerlies prevail there in observations 
a)

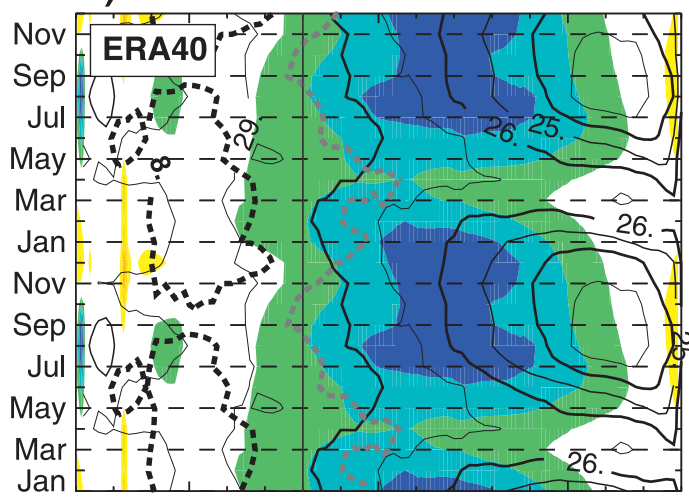

c) $150 \mathrm{E}$

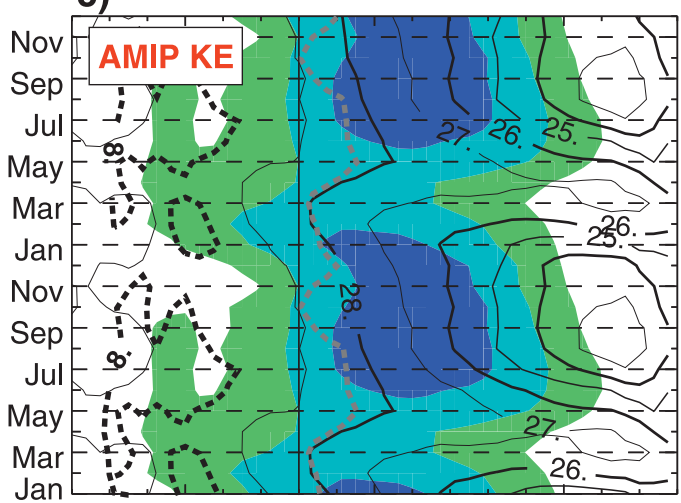

e) $150 \mathrm{E}$

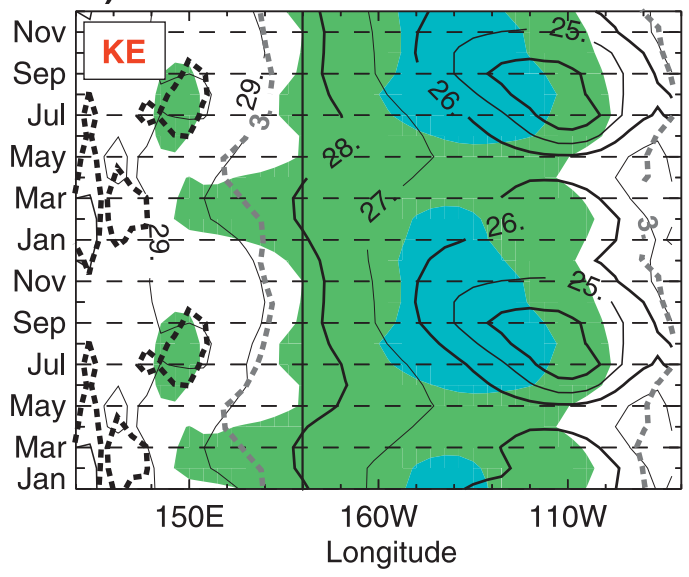

b)
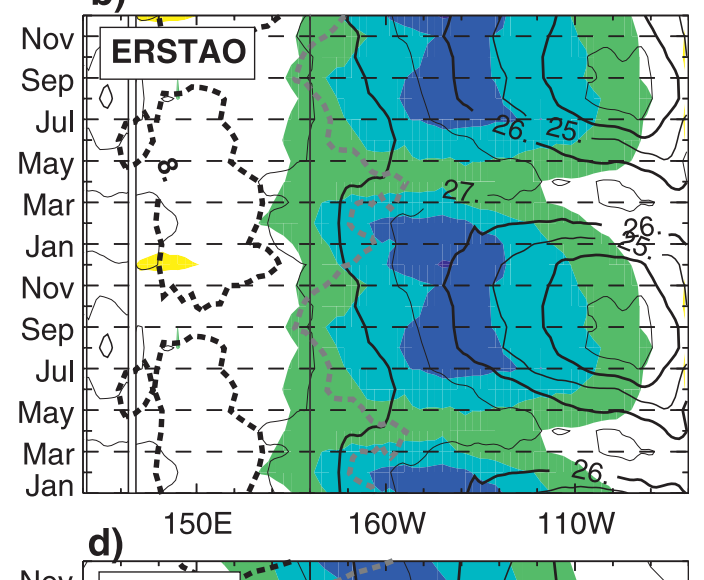
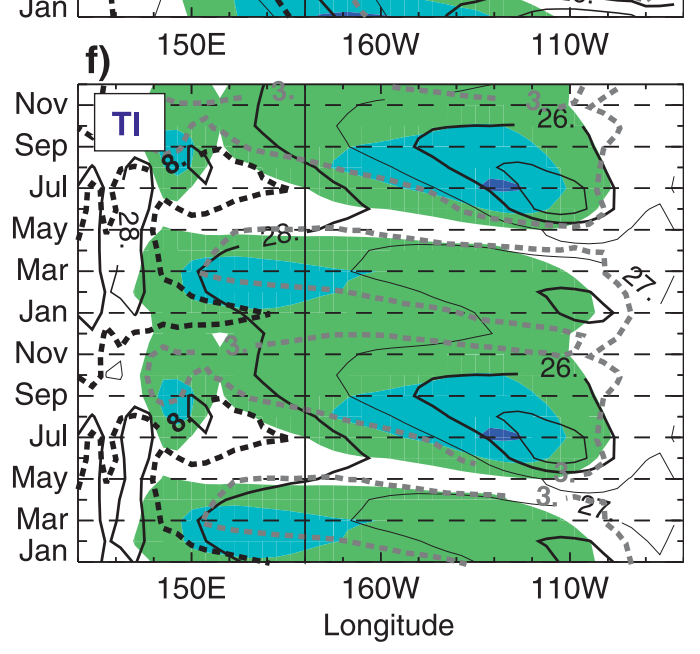

N.m-2

$$
\begin{array}{llllll}
-0.10 & -0.06 & -0.02 & 0.02 & 0.06 & 0.10
\end{array}
$$

FIG. 2. Annual cycle along the equator (averaged between $2^{\circ} \mathrm{N}$ and $2^{\circ} \mathrm{S}$ and reproduced twice) for zonal wind stress (shading), SST (contours), and precipitation (thick dashed contours). Contour interval for SST is $1^{\circ} \mathrm{C}$; precipitation contours are 3 and $8 \mathrm{~mm} \mathrm{day}^{-1}$. (a) ERA-40 zonal wind stress and SST with CMAP precipitation (1958-2001); (b) ERS TAO wind stress, HadISST1.1 SST, and CMAP precipitation (1992-98); (c) AMIP-KE (1979-2002); (d) AMIP-TI (1979-2002). (e) coupled simulation KE (100 years); and (f) coupled simulation TI (100 years).

(Figs. 2a and 2b). The feedbacks between convection, large-scale circulation, SST, and clouds maintain the ITCZ in a realistic position in KE (not shown, see B07). As already pointed out by B07, the origin of these qualities and systematic errors can partly be traced back to the atmospheric GCM (see also Lin 2007; Sun et al. 2008). When forced by observed SST, AMIP-KE produces easterlies and precipitation that broadly agree 
with observations (Fig. 2c). Nevertheless, the easterlies are too strong in $\mathrm{NH}$ winter/spring and the structures are shifted westward by about $10^{\circ}-20^{\circ}$, especially over the warm pool. These biases are then amplified in the coupled model (Fig. 2e).

The seasonal cycle in the equatorial Pacific is degraded in TI when compared to KE (Fig. 2f). In the east, this involves a weaker annual cycle, a stronger semiannual cycle (an additional spurious relaxation of the easterlies is seen in the NH autumn), and reduced upwelling. In the west Pacific, there is a much stronger annual cycle, and the intensification of the easterlies in $\mathrm{NH}$ winter (weakly present in KE) is dramatically increased here and reaches the amplitude of the $\mathrm{NH}$ summer east Pacific easterlies. The deep convection spuriously migrates east of the date line and reached the South American coast during the two easterly relaxation periods (April-June and November-December). Accordingly, the mean zonal SST gradient across the equatorial Pacific is reduced by $1.4^{\circ} \mathrm{C}$ in TI when compared to KE. Meridionally, the ITCZ is too far south, close to the equator, and the spurious semiannual cycle is associated with a strong spurious double ITCZ (B07). Again, these biases can be traced back to the AMIP-TI simulation (Fig. 2d). Even forced by observed SST, the spurious secondary maximum of easterlies is seen extending west of the date line from October to March. The deep convection also moves much too far to the east and reaches the South American coast during the $\mathrm{NH}$ spring relaxation.

B07 attributes the east Pacific biases in TI to the impact of the modified convection scheme on the South American monsoon regime. In KE, the added representation of downdrafts allows a similar intensity of convection over land and over the ocean whereas, in TI, the deep convection over the ocean is much stronger than over land (Fig. 14 in B07). This results in intensified monsoon winds in the east Pacific that disrupt the seasonal cycle, especially during spring and autumn. Indeed, the equinoctial asymmetric precipitation monsoon mode (which measures the April-May minus OctoberNovember mean precipitation difference, Wang and Ding 2008) is much too strong in AMIP-TI when compared to AMIP-KE, whereas the solstitial mode (measuring the winter minus summer precipitation difference) is not changed much (not shown). These biases during the equinoxes modify the global circulation of the tropical Pacific and contribute to the basinwide biases seen both in AMIP-TI and TI during these periods.

In the ocean, the depth of the mean thermocline, as measured by the zonal $20^{\circ} \mathrm{C}$ isocontour depth, is not changed much between KE and TI (Fig. 3). The nearequatorial thermocline is slightly deeper for TI (about

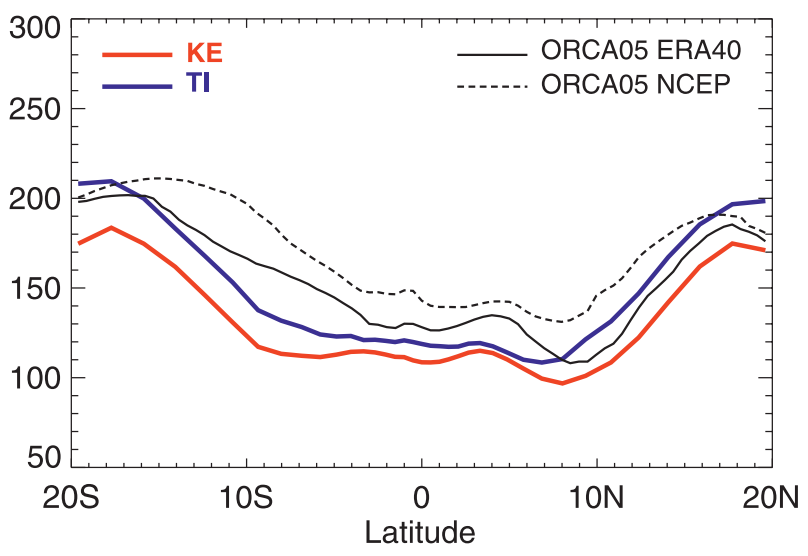

FIG. 3. Zonal-mean thermocline depth in the tropical Pacific as defined by the $20^{\circ} \mathrm{C}$ isotherm depth (m): KE (solid red), TI (solid blue), ORCA05 CORE NCEP2 (solid black), and ORCA05 CORE ERA-40+ (dashed black).

$10 \mathrm{~m}$ ), which will somewhat weaken ENSO-related thermocline feedback ( $\mathrm{Li}$ 1997b) but not to the point of suppressing ENSO (Fig. 1). As a comparison, the mean thermocline depth of two forced ocean models differing by the wind product used (ERA-40 and NCEP) shows similar differences.

\section{Simulated ENSO properties}

As already seen in Fig. 1, the ENSO amplitude is diminished by a factor of $\sim 3$ from KE to TI [the Niño-3 $\left(5^{\circ} \mathrm{S}-5^{\circ} \mathrm{N}, 150-90^{\circ} \mathrm{W}\right) \mathrm{SST}$ anomaly (SSTA) standard deviation has decreased from $1^{\circ}$ to $\left.0.34^{\circ} \mathrm{C}\right]$. To understand the mechanisms that led to such a dramatic change, El Niño composites are devised by using events for which the SSTA in Niño-3 is larger than 1.5 standard deviation (four events in HadISST1.1, five in KE, and nine in TI; Fig. 4). This criterion only picks up the large El Niño events; this is justified as the change in ENSO properties between KE and TI is very large. It was checked that relaxing the threshold to 1.3 standard deviations does not change the results discussed below. The El Niño composite for KE exhibits a correct amplitude and time evolution when compared to observations, even though the amplification phase in the $\mathrm{NH}$ spring of year 0 is stronger than in observations and the decay also starts earlier. In TI, the amplitude is very weak, as expected from Fig. 1. For both simulations, the interevent differences are small enough so that the composite is a good representation of each event (not shown). Composites are also devised for the AMIP simulations, which include the 1982-83 and 1997-98 El Niño events, and for the different reference data. Both atmospheric feedbacks (dynamical and heat flux) are then analyzed. 

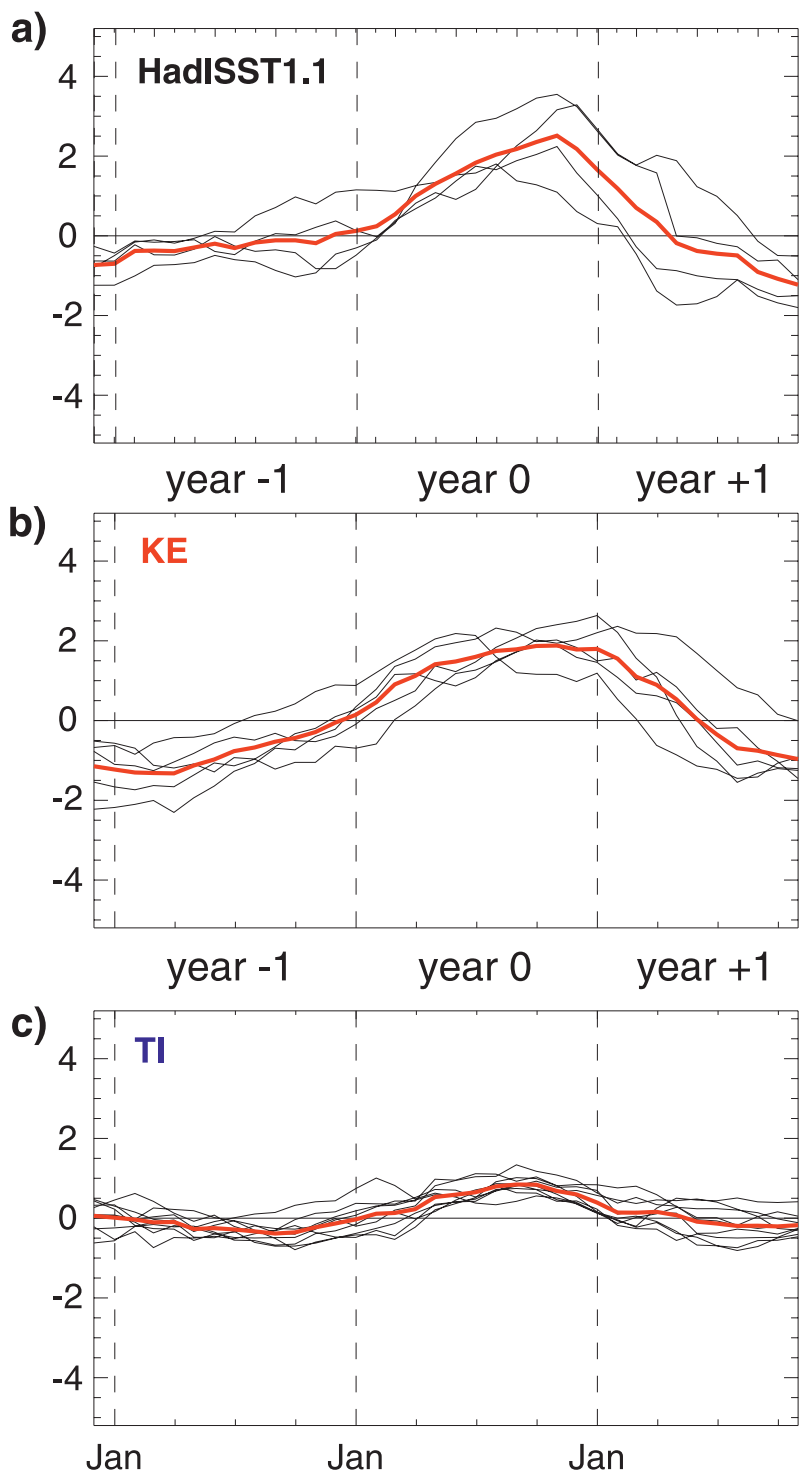

FIG. 4. Niño-3 SST anomaly depicting individual El Niño events (thin black curves) and composites (thick red curve), selected as exceeding 1.5 standard deviation in Niño-3 SSTA for (a) HadiSST1.1 (50 years, four events: 1972, 1982-83, 1987-88, and 1997-98), (b) KE (100 years, five events), and (c) TI (100 years, nine events).

The equatorial anomalies of the composite zonal wind stress $\tau_{x}$ (shading) and SST (contours) in the Pacific are shown in Fig. 5. Here, reference fields include both the ERA-40 and the NCEP reanalysis (Figs. 5a and 5b). In both cases, the westerly wind stress anomaly that propagates eastward in year 0 is associated with the El Niño warming through the Gill (1980) atmosphere response and via the Bjerknes feedback. Both AMIP-KE (Fig. 5c) and AMIP-TI (Fig. 5d) exhibit a similar wind stress response to the forced SST. The magnitude of the response is slightly larger in KE (the next section will quantify these differences), and both AMIP simulations show an increase of easterlies in the east of the basin, associated with the westward shift of the wind structure (Figs. 2c and 2d). In KE, the zonal wind stress also exhibits a westerly anomaly associated with weakened easterlies, albeit much weaker than in AMIP-KE (Fig. 5e). The SST anomaly structure is shifted westward, as also seen in Fig. 1. Unlike the observations and the AMIP simulations, the eastward propagation of the wind stress anomaly envelope is not very clear. This may be partly due to the dominance of the SST mode in this model, whereas observations (especially the 1982-83 and the 1997-98 events) also exhibit a thermocline mode, which involves eastward propagation (Trenberth and Stepaniak 2001; Guilyardi 2006; Lengaigne and Vecchi 2009). In $\mathrm{TI}$, the interannual anomalies are quite small since ENSO is mostly suppressed.

To describe the heat flux feedback, the equatorial anomalies of the composite total downward surface heat flux (shading) and SST (contours) in the Pacific are shown in Fig. 6. Here reference fields include both ERA-40 and OAFlux (Figs. 6a and 6b; the radiative components of the OAFlux dataset are taken from ISCCP). Even though surface fluxes in the different analysis available exhibits marked differences (Wittenberg et al. 2006), both products show strong heat flux damping during El Niño, mostly collocated with positive SST anomalies. The amplitude is weaker for the ERA-40 composite, which may be due to the larger number of El Niño events included. For the OAFlux composite, which only includes the 1997-98 event, the heat flux anomaly reaches -80 to $-100 \mathrm{~W} \mathrm{~m}^{-2}$ in large areas of the central eastern Pacific in January-February of year +1 . In the AMIP-KE composite, the heat flux feedback reaches $-60 \mathrm{~W} \mathrm{~m}^{-2}$ in the central Pacific, whereas it reaches -100 to $-120 \mathrm{~W} \mathrm{~m}^{-2}$ in AMIP-TI. In KE, the heat flux anomaly is not collocated with the SST anomaly but on the SST zonal gradient near the date line and is also weaker, reaching only $-40 \mathrm{~W} \mathrm{~m}^{-2}$ (Fig. 6e), indicating a different balance of physical mechanisms east of the date line. In TI, the interannual anomalies are also quite small since ENSO is mostly suppressed even though they are collocated with the SST anomalies.

\section{Mechanisms for ENSO suppression in TI}

The analysis presented so far strongly suggests that the increased heat flux feedback in TI is responsible for the ENSO suppression in this simulation. To verify this hypothesis, the Bjerknes (BJ) index and its components (Jin et al. 2006) are computed for KE and TI (Table 1). The BJ index measures the ENSO linear growth rate based on the recharged oscillator theory (Jin 
a)

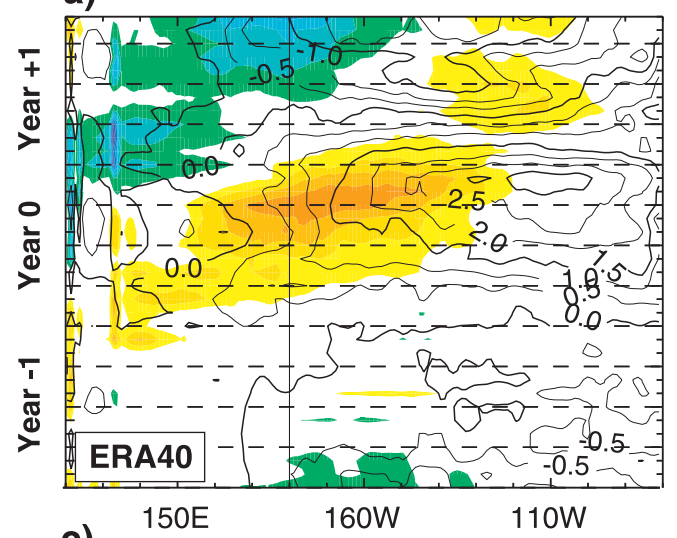

c)

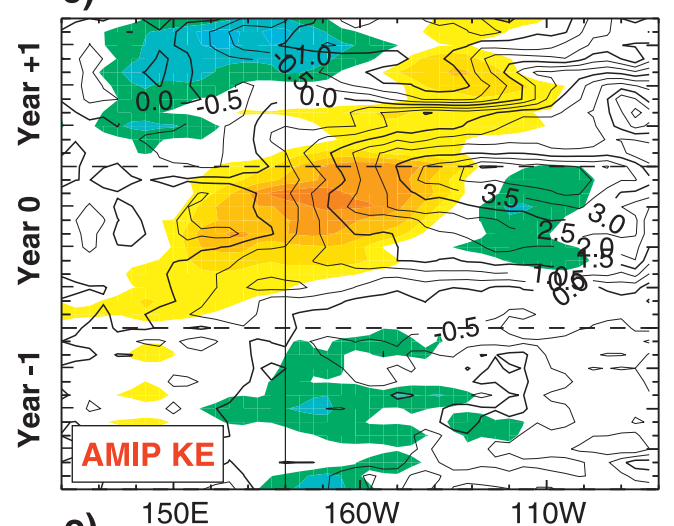

e)

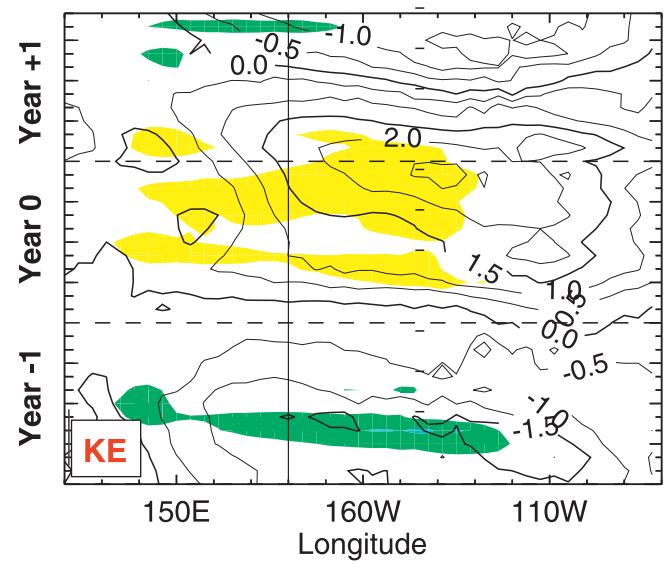

b)

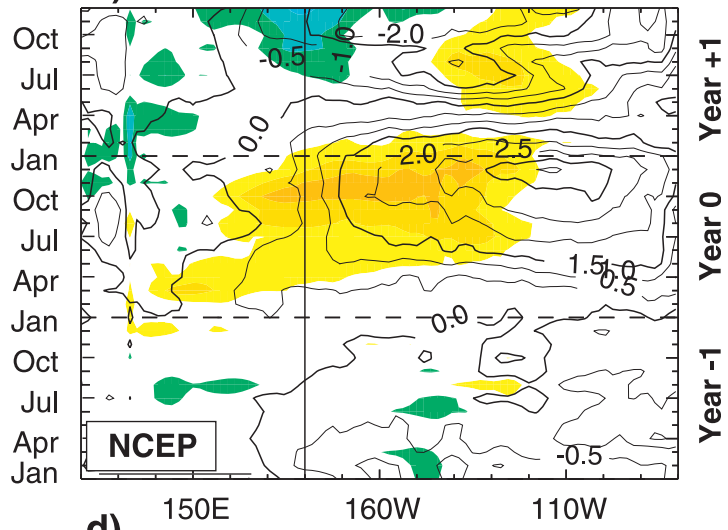

d)

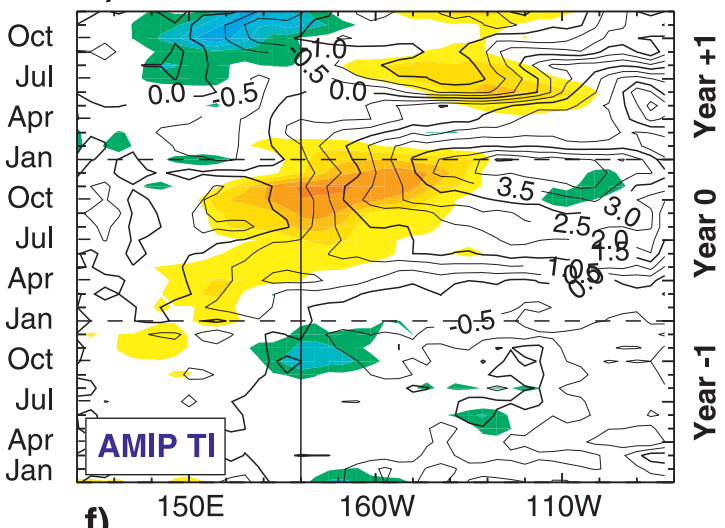

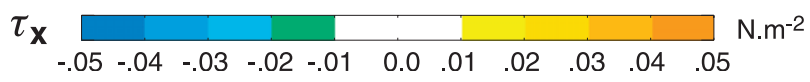

FIG. 5. Composite El Niño evolution along the equator for zonal wind stress anomaly (shading) and SST anomaly (contour interval 0.5 C): (a) ERA40, (b) NCEP2, (c) AMIP-KE, (d) AMIP-TI, (e) KE, and (f) TI.

1997). The strongly negative BJ index for TI confirms that the balances of processes damps the development of ENSO in this simulation. All components of the BJ index contribute to the overall weakening in TI when compared to KE (Table 1). Nevertheless, the largest contribution to the decrease is by far the negative feed- back due to the thermodynamic damping $(\alpha)$, which is multiplied by 3 , from $-0.45 \mathrm{yr}^{-1}$ to $-1.33 \mathrm{yr}^{-1}$. The ocean feedbacks (including the zonal advective feedback, the thermocline feedback, and the Ekman feedback; for details see Jin et al. 2006; P. Kim and F.-F. Jin (2009, personal communication) as well as the dynamical 
a)
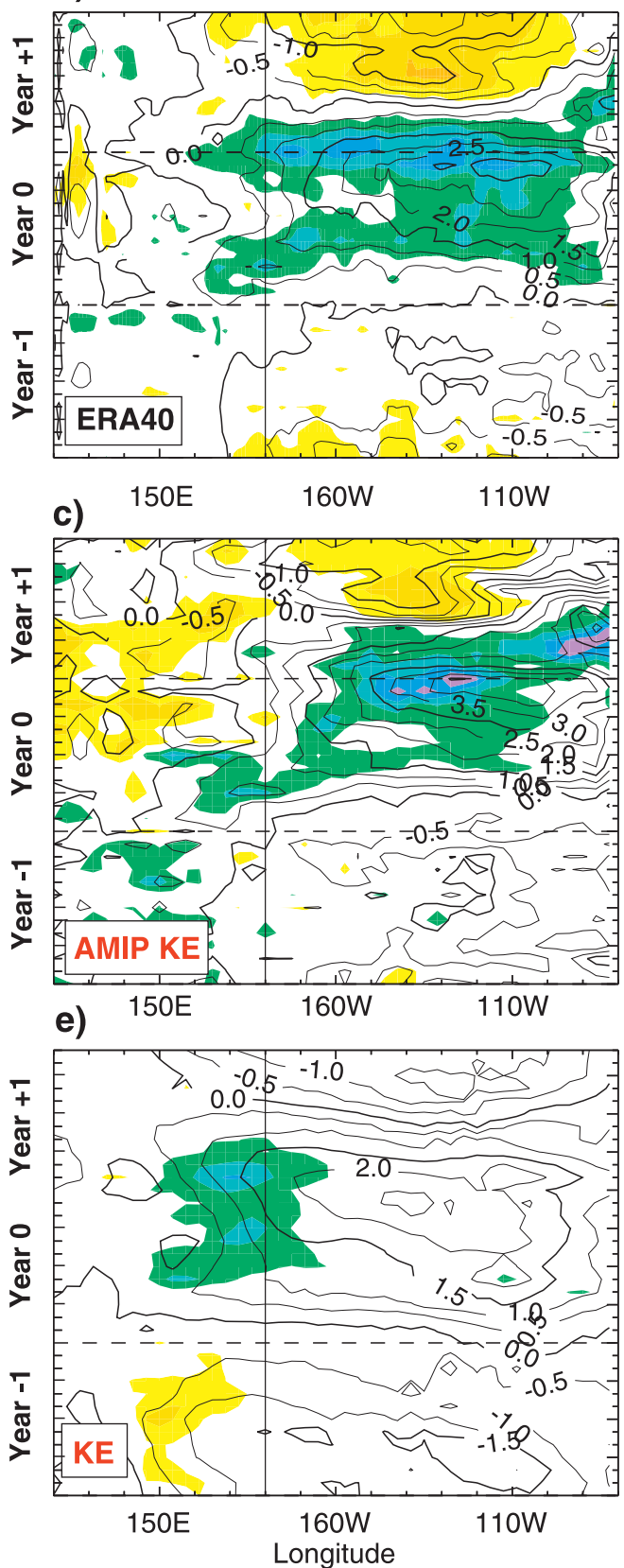

b)
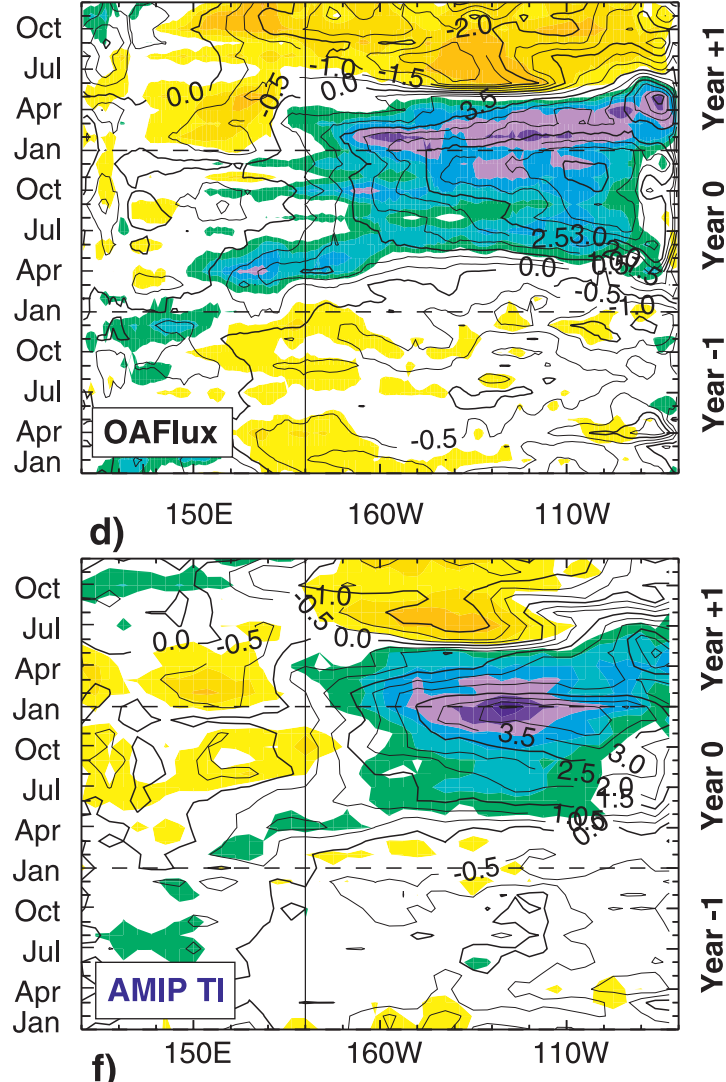

Oct

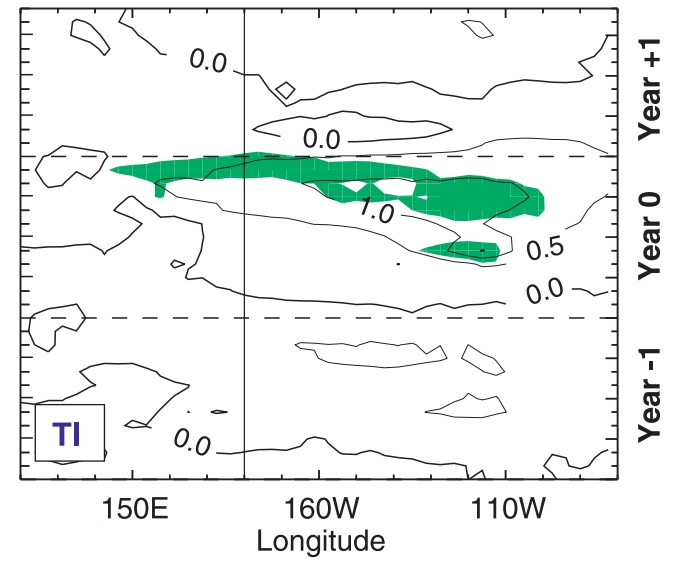

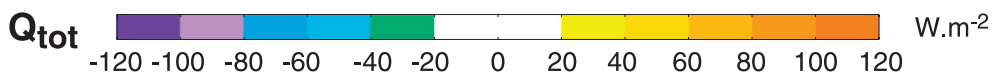

FIG. 6. As in Fig. 5 but for total heat flux anomaly (shading) and SST (contours). The reference in (b) is now OAFlux (which includes ISCCP radiative fluxes; 1984-2001).

damping (associated with the background state) also play a role, but of lesser amplitude. Most of the ocean feedback change is due to the weakening of the thermocline positive feedback, associated with the deeper mean thermocline (Fig. 3).
A rapid heat budget analysis further shows that the AMIP-KE/AMIP-TI heat flux difference of $-50 \mathrm{~W} \mathrm{~m}^{-2}$ (Figs. 6c and 6d) over a 50-m-thick mixed layer (typical of the central/east Pacific) modifies the SST tendency by $-1^{\circ} \mathrm{C}$ month ${ }^{-1}$ (equivalent to an additional damping 
TABLE 1. The BJ index and its components for KE and TI simulations. The ocean feedback is the sum of the zonal advective feedback, thermocline feedback, and Ekman feedback (see Jin et al. 2006 for details). Units are $1 \mathrm{yr}^{-1}$.

\begin{tabular}{lcccr}
\hline \hline & $\begin{array}{c}\text { Dynamic } \\
\text { damping }\end{array}$ & $\begin{array}{c}\text { Thermodynamic } \\
\text { damping }(\alpha)\end{array}$ & $\begin{array}{c}\text { Ocean } \\
\text { feedback }\end{array}$ & $\begin{array}{c}\text { BJ } \\
\text { index }\end{array}$ \\
\hline KE & -0.46 & -0.45 & 1.02 & $\mathbf{0 . 1 1}$ \\
TI & -0.61 & -1.33 & 0.52 & $-\mathbf{1 . 4 2}$ \\
Change (\%) & -30 & -200 & -50 & \\
\hline
\end{tabular}

rate of $(6 \text { weeks })^{-1}$; see also Burgers and van Oldenborgh 2003), a value large enough to cancel the development of ENSO, as suggestedr by the BJ index analysis above.

\section{a. Heat flux feedback components}

To understand the detail of these heat flux feedback changes, the components of the surface heat flux are now analyzed. Figures 7 and 8 show the composite evolution at the equator in the Pacific Ocean of the SHF (and total cloud cover in contours) and the LHF (and the meridional wind stress in contours), both of which are the dominant contributors to the total heat flux changes in the tropics. In ERA-40 and ISCCP (Figs. 7a and $7 \mathrm{~b}$ ), the SHF reduction reaches about $-60 \mathrm{~W} \mathrm{~m}^{-2}$ and is associated with the increased cloud cover due to the eastern migration of the deep atmosphere convection over warm waters. This feedback is mostly occurring at the end of the warming episode due to the time required to build up a large enough SST to trigger convection. In AMIP-KE, the associated negative shortwave feedback is weaker (in an integral sense, that is, both the maximum and the extension are weaker), and becomes positive in the eastern part of the basin where heating destabilizes the boundary layer and reduces the stratiform cloud cover (Norris and Leovy 1994; Li and a)

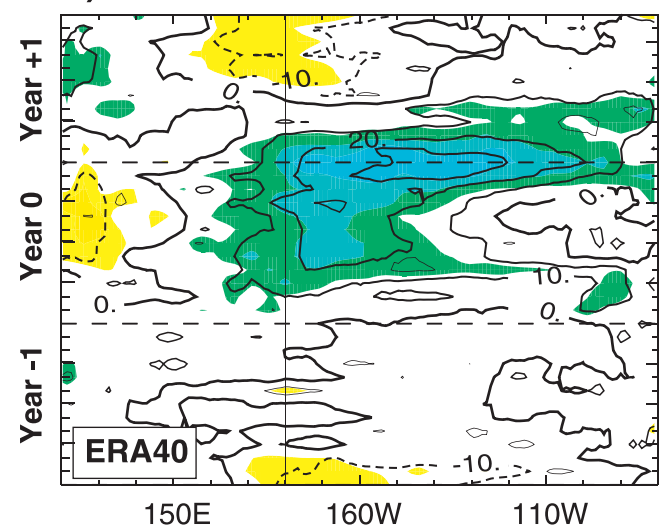

c)

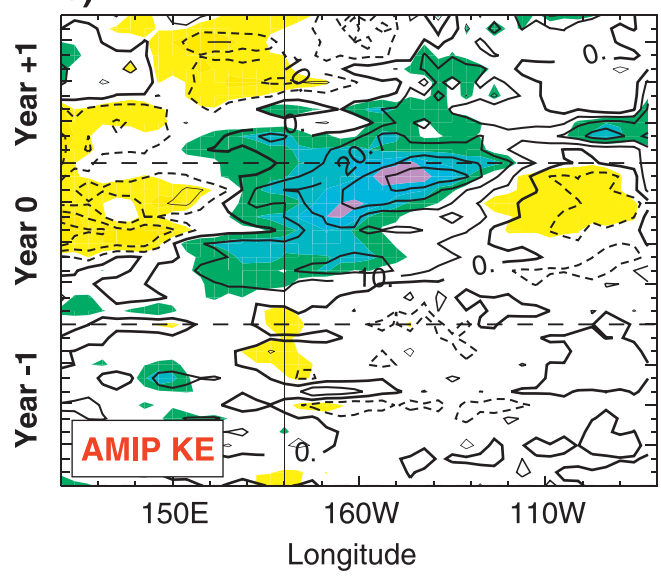

b)

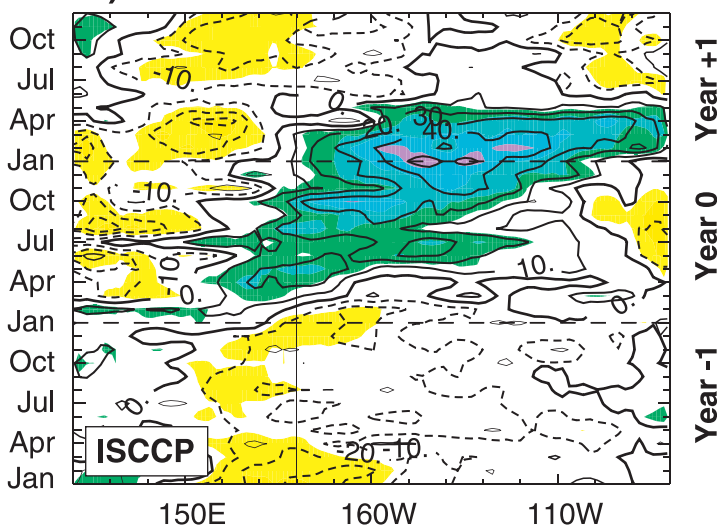

d)

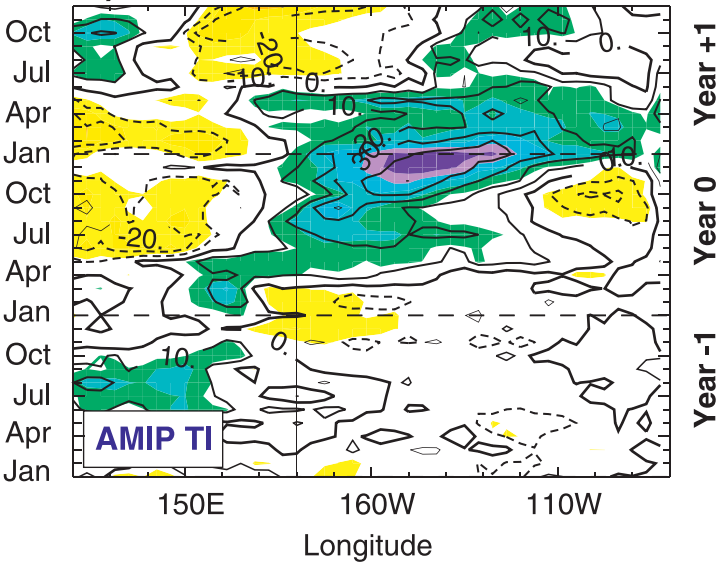

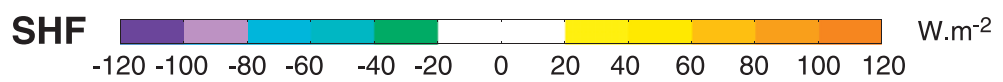

FIG. 7. As in Figs. 5a-d but for SHF (shading) and total cloud cover (contour interval for cloud cover: $10 \%$ ). 
a)

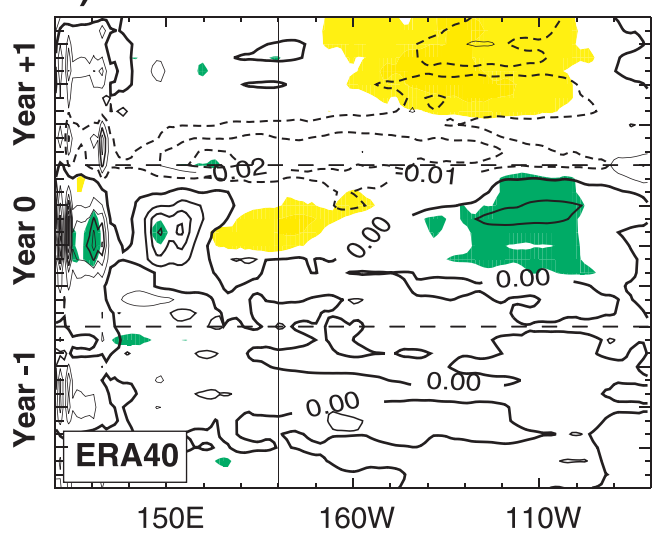

c)

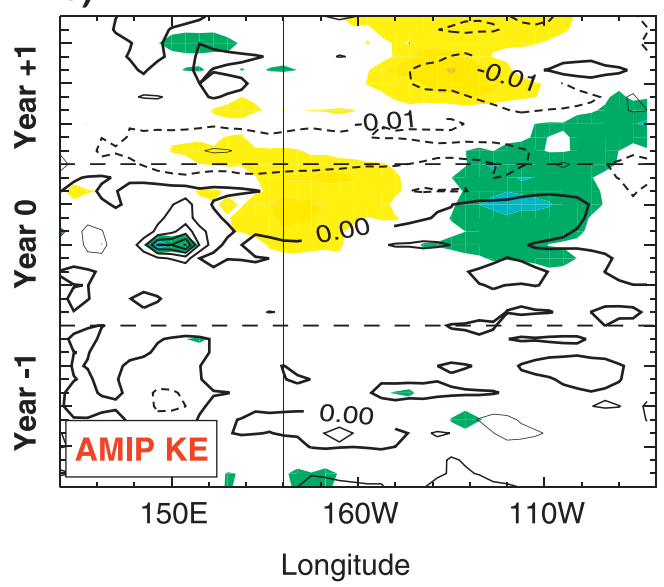

b)

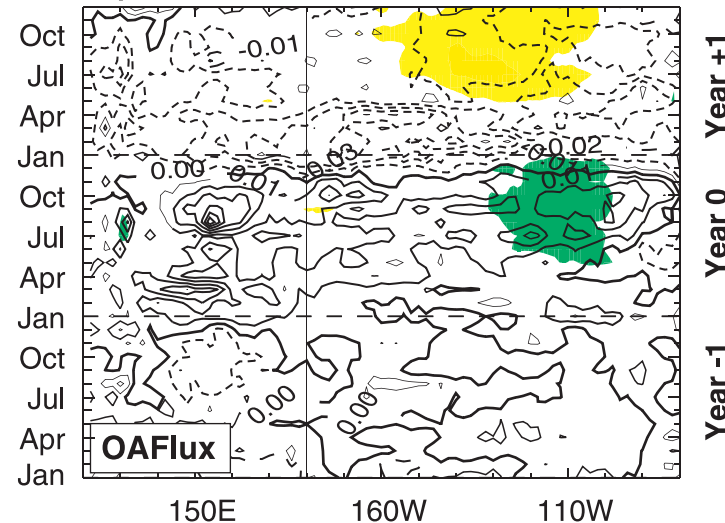

d)

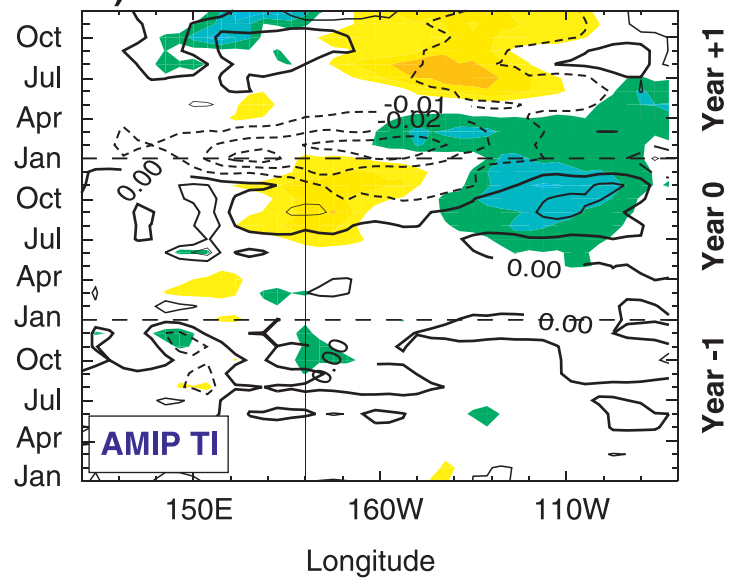

\section{LHF}

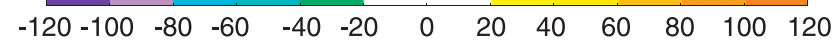

W.m-2

FIG. 8. As in Fig. 7 but for LHF (shading) and meridional wind stress $\tau_{y}$ (contour interval for $\tau_{y}: 0.01 \mathrm{~N} \mathrm{~m}^{-2}$ ).

Philander 1996). In AMIP-TI the negative SHF feedback is much stronger since the convection in TI is also stronger, leading to a much increased cloud cover for the same SST anomaly (Fig. 7d, see also B07).

The latent heat flux feedback in ERA-40, and to a lesser degree in OAFlux (Figs. 8a and 8b), exhibits a zonal dipole with reduced latent heat flux loss (hence the positive anomalous LHF) in the central and west Pacific and increased latent heat flux east of $150^{\circ} \mathrm{W}$. The reduction in the central and west Pacific is due to the relaxation of the trade winds that occurs during ENSO in this region. In the east Pacific, the increase is due to the increased meridional wind (Figs. $8 \mathrm{a}$ and $8 \mathrm{~b}$ ) that dominates the mean wind speed in this region (Chelton et al. 2001). These features are well simulated by both AMIP simulations, and the positive anomalous LHF is of comparable intensity in the central and west Pacific. On the other hand, the AMIP-TI feedback is larger in the east Pacific ( $+20 \mathrm{~W} \mathrm{~m}^{-2}$ in the Niño-3 region). The increased meridional wind change in AMIP-TI is responsible for this change (Fig. 8d). This feature is associated with the convergence due to increased convection in the ITCZ in AMIP-TI and the too southerly location of the ITCZ, reaching the equatorial waveguide (see B07). Hence, both the SHF and LHF feedback in AMIP-TI can be traced back to the modified convection scheme, which leads to stronger deep convection over the equatorial ocean compared to AMIP-KE.

\section{b. Quantification of atmospheric feedbacks}

To further quantify the dynamical $(\mu)$ and heat flux feedback $(\alpha)$ in the east Pacific, the corresponding interannual anomalies are regressed onto the Niño-3 SST anomalies (Figs. 9 and 10). The slope of the linear regression measures the intensity of the feedback. For $\mu$ [measured here as the Niño-4 zonal wind stress anomaly 

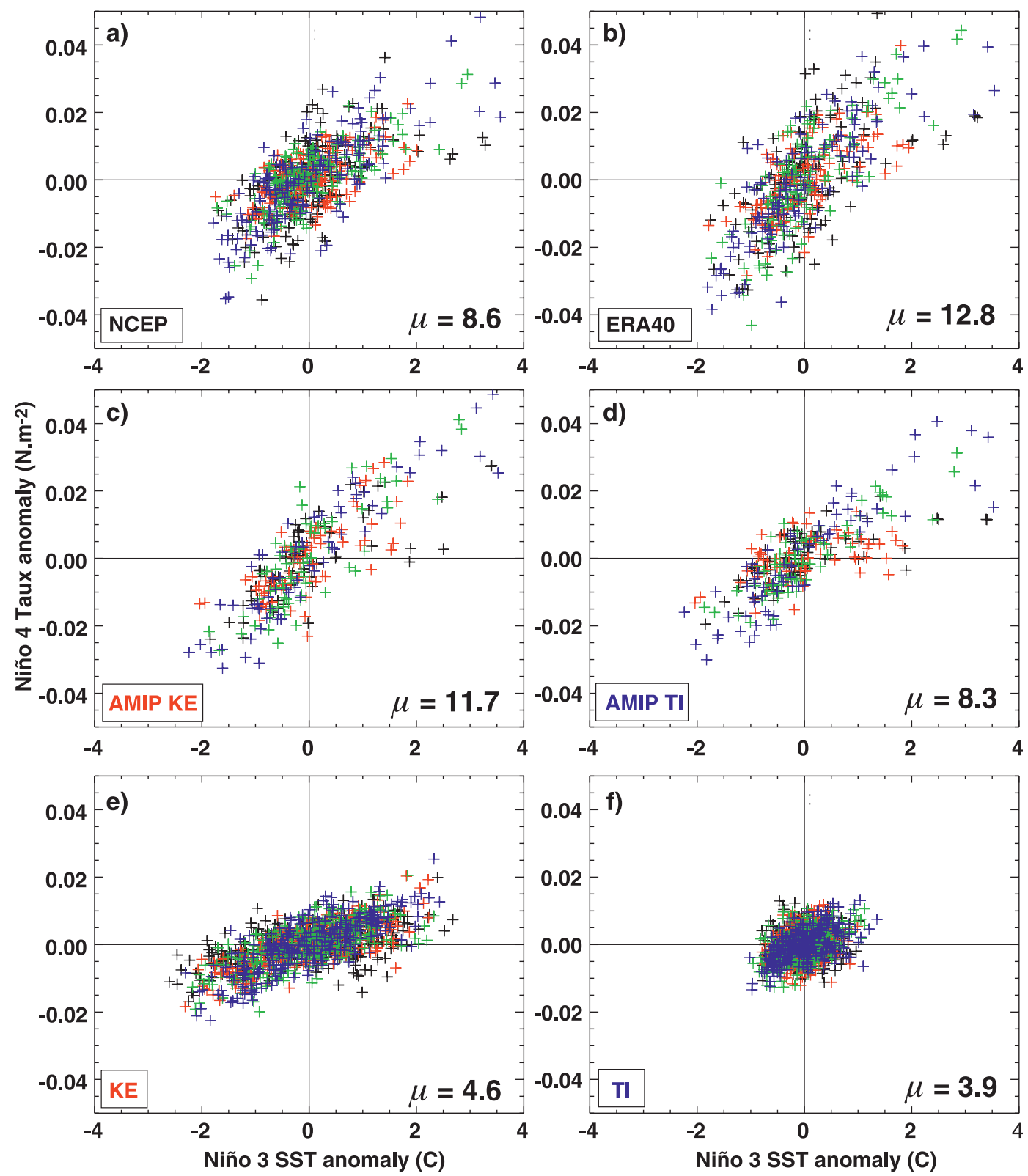

FIG. 9. Scatterplot of monthly Niño-4 zonal wind stress anomaly as a function of monthly Niño-3 SSTA for (a) NCEP2, (b) ERA40, (c) AMIP-KE, (d) AMIP-TI, (e) KE, and (f) TI. The slope of the linear regression measures the coupling strength $\mu$, as indicated in units of $10^{-3} \mathrm{~N} \mathrm{~m}^{-2} \mathrm{C}^{-1}$. Colors indicate different seasons: Dec-Feb (black), Mar-May (blue), Jun-Aug (red), and Sep-Nov (green).

regressed onto the Niño-3 SST anomaly, both regions being the maximum variability zone for the corresponding fields, according to Gill (1980); not shown], the reference values are $8.6 \times 10^{-3} \mathrm{~N} \mathrm{~m}^{-2} \mathrm{C}^{-1}$ for NCEP-2 and $12.8 \times 10^{-3} \mathrm{~N} \mathrm{~m}^{-2} \mathrm{C}^{-1}$ for ERA-40 (Figs. 9a and 9b). Both AMIP simulations have values within this range, as suggested by Fig. 5, with the AMIP-TI being somewhat weaker (Figs. 9c and 9d). With a value of $4.6 \times 10^{-3} \mathrm{~N} \mathrm{~m}^{-2} \mathrm{C}^{-1}$, the KE simulation (Fig. 9e) ex- hibits a much weaker dynamical feedback than its AMIP counterpart. Similarly the TI simulation has a much weaker dynamical feedback, although the range of SST anomalies is much reduced due to the suppressed ENSO (Fig. 9f).

The average total heat flux feedback $(\alpha)$ in the Niño-3 region is $-19 \mathrm{~W} \mathrm{~m}^{-2} \mathrm{C}^{-1}$ in ERA-40 and $-17 \mathrm{~W} \mathrm{~m}^{-2} \mathrm{C}^{-1}$ in OAFlux (Figs. 10a and 10b). Note that this value drops to about $-10 \mathrm{~W} \mathrm{~m}^{-2} \mathrm{C}^{-1}$ for 

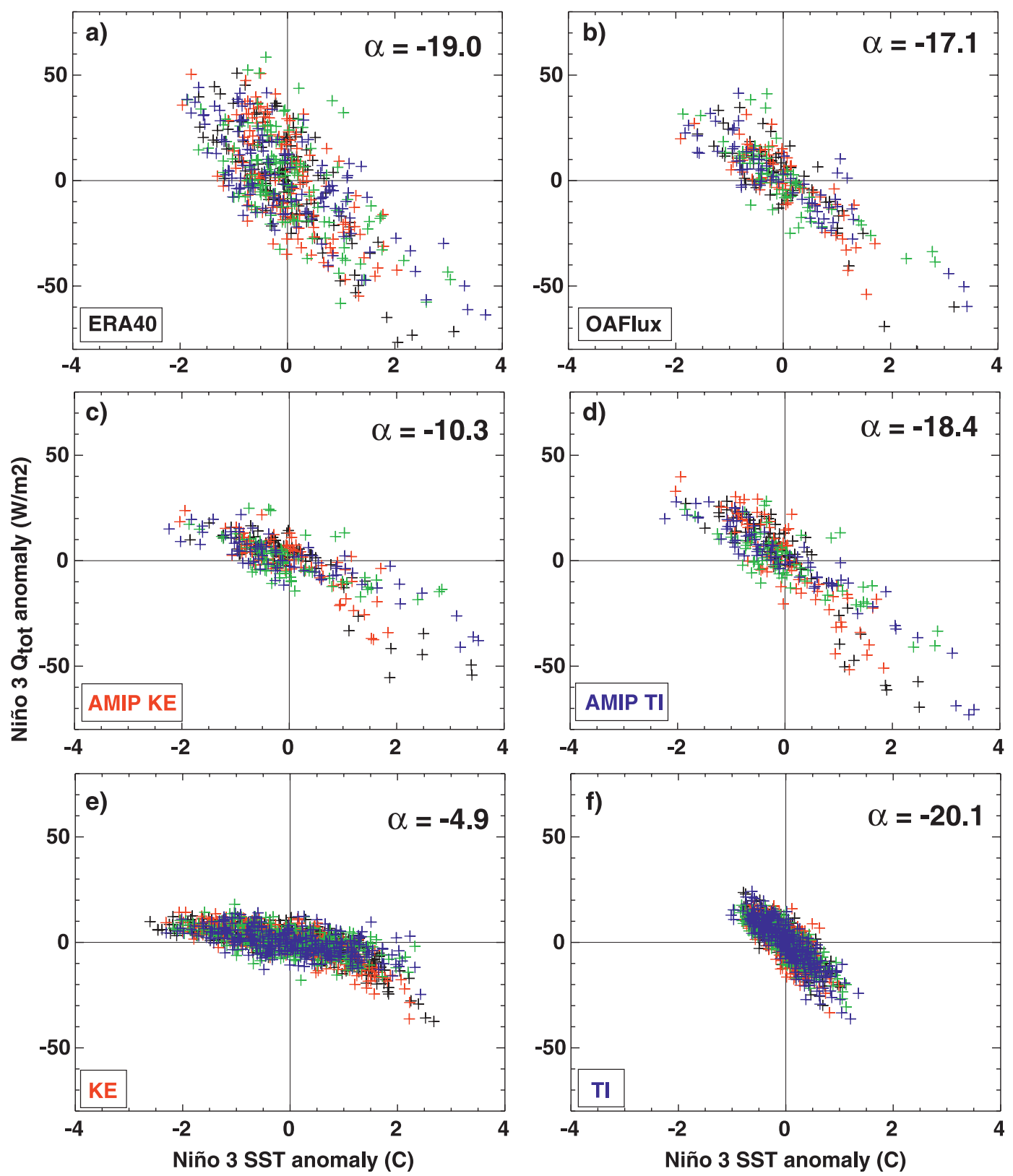

FIG. 10. As in Fig. 9 but for the monthly Niño-3 total heat flux anomaly as a function of the Niño-3 SST anomaly. The slope of the linear regression measures the heat flux feedback $\alpha$, as indicated in units of $\mathrm{W} \mathrm{m}^{-2} \mathrm{C}^{-1}$. (a) ERA40, (b) OAFlux/HadISST1.1, (c) AMIP-KE, (d) AMIP-TI, (e) KE, and (f) TI.

NCEP-2 (not shown), whose surface heat fluxes are subject to larger errors in the east Pacific (Cronin et al. 2006). In AMIP-KE $\alpha$ is only $-10 \mathrm{~W} \mathrm{~m}^{-2} \mathrm{C}^{-1}$, whereas it reaches the reference value of $-18 \mathrm{~W} \mathrm{~m}^{-2} \mathrm{C}^{-1}$ in AMIP-TI, as also suggested by Fig. $6 \mathrm{~d}$. Again, $\alpha$ in KE is much reduced $\left(-4.9 \mathrm{~W} \mathrm{~m}^{-2} \mathrm{C}^{-1}\right.$; Fig. 10e) when compared to AMIP-KE. On the other hand, TI exhibits an $\alpha$ similar to AMIP-TI $\left(-20 \mathrm{~W} \mathrm{~m}^{-2} \mathrm{C}^{-1}\right)$, although still with a much reduced range of SST anomalies (Fig. 10f). As discussed in the introduction, the mean resulting $\alpha$ in the east Pacific is a mix of several regimes (in which $\alpha$ varies and even changes sign), as suggested from the nonlinearity of the SHF-SST anomalies relation (Fig. 10). This aspect will be investigated in more detail in the next section.

Even though most theoretical studies use an annual mean value for $\mu$ and $\alpha$, these exhibit a marked seasonal cycle (Fig. 11). In both reanalyses, the positive dynamical feedback is strongest from July onward, when ENSO is amplified via the Bjerknes feedback, and peaks during October-November just before ENSO itself peaks 
a) Bjerknes feedback $\mu$

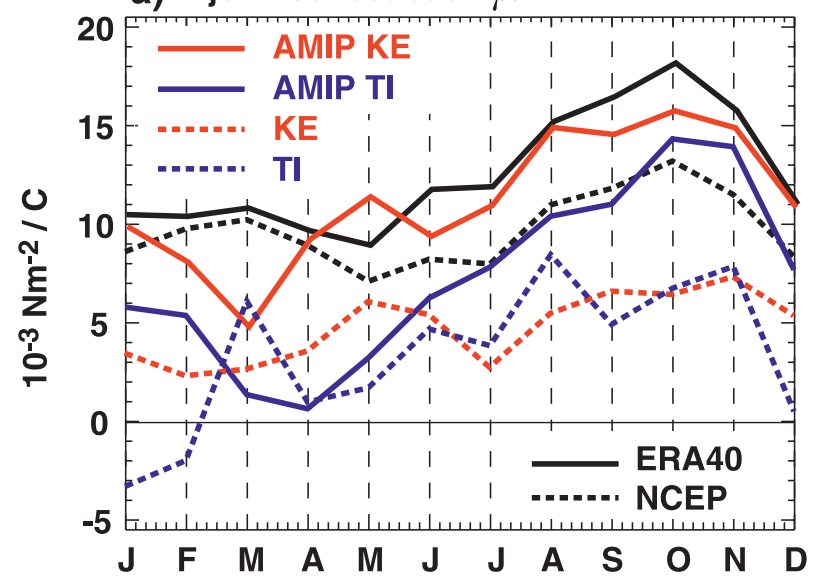

b) Total heat flux feedback $\alpha$ (Niño 3)

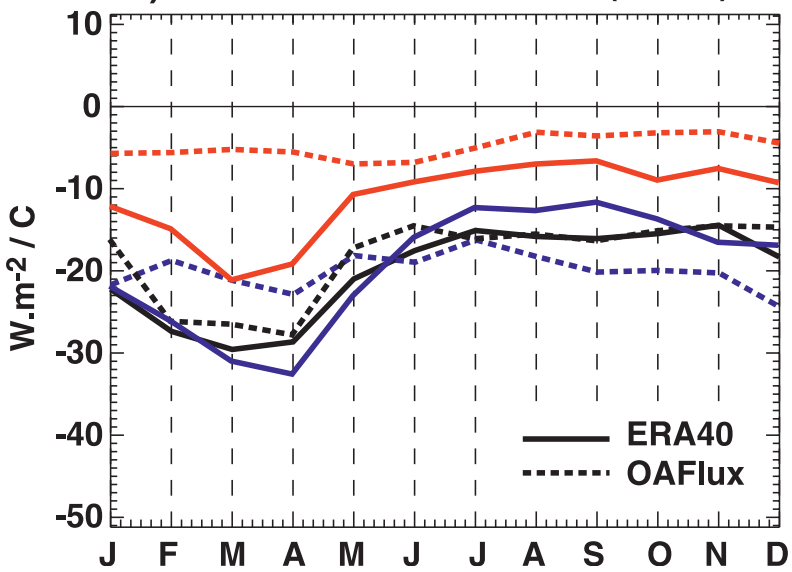

FIG. 11. Monthly evolution of (a) $\mu$ and (b) $\alpha$ as defined in Figs. 9 and 10, ERA-40 (solid black), NCEP (for $\mu$ ) or OAFlux (for $\alpha$ ) (dashed black), AMIP-KE (solid red), AMIP-TI (solid blue), KE, (dashed red), and TI (dashed blue).

(Fig. 11a). On the other hand, the heat flux feedback is strongest from about January to May (when its value doubles from $-15 \mathrm{~W} \mathrm{~m}^{-2} \mathrm{C}^{-1}$ during the rest of the year to $-30 \mathrm{~W} \mathrm{~m}^{-2} \mathrm{C}^{-1}$ ), when ENSO anomalies are reduced and/or ENSO is not yet developing. This seasonal evolution of the atmosphere feedbacks can therefore partly explain the ENSO seasonal phase lock and suggests a physical explanation to the results obtained from linear stability analysis in which ENSO is damped in $\mathrm{NH}$ winter and spring, whereas it is amplified during the rest of the year (Li 1997a; Li and Hogan 1999; Fedorov and Philander 2001).

In the AMIP simulations, $\mu$ also exhibits a maximum in NH autumn with AMIP-KE having about the correct magnitude then and AMIP-TI having too weak values, especially in $\mathrm{NH}$ spring (Fig. 11a). The dynamical feedback in both models is reduced in coupled mode, and the seasonality disappears. Nevertheless and as described before, the intensity of the dynamical feedback is similar with both convection schemes, and $\mu$ changes cannot explain the drastic change of ENSO behavior seen in TI. The heat flux feedback also has the correct seasonal behavior in the AMIP simulations (Fig. 11b). Nevertheless, while the AMIP-TI follows the reanalysis quite well, the AMIP-KE $\alpha$ is too weak by $50 \%$ year round. This bias is strongly amplified in KE, whereas $\alpha$ in TI remains closer to the reanalysis value, albeit with a loss of seasonality. This loss of seasonality also results in a stronger negative feedback in $\mathrm{NH}$ summer and autumn, which further damps ENSO development. The analysis of the SHF and LHF components of $\alpha$ (Fig. 12) shows that the difference between AMIP-KE and AMIP-TI is mostly due to $\alpha_{\mathrm{SW}}$, although $\alpha_{\mathrm{LH}}$ contributes as well to the difference in NH spring when $\alpha$ is strongest. In coupled mode, $\alpha_{\mathrm{SW}}$ accounts for all the difference between KE and TI (Figs. 12a and 12b).

To verify that changes in $\alpha_{\mathrm{SW}}$ can indeed explain the large change of ENSO amplitude between TI and KE, a sensitivity simulation is made with the $\mathrm{KE}$ atmospheric physics. In this simulation, called KE-mod, an interannual flux correction is performed to artificially change $\alpha_{\mathrm{SW}}$ to a value close to that of TI $\left(-15 \mathrm{~W} \mathrm{~m}^{-2} \mathrm{C}^{-1}\right.$, see green dashed curve in Fig. 12a). The interannual flux correction is imposed throughout the tropics between $30^{\circ} \mathrm{S}$ and $30^{\circ} \mathrm{N}$, using the following relation:

$$
\operatorname{SHF}_{O}=\operatorname{SHF}_{O}^{\mathrm{SCref}}+\alpha_{\text {SWmod }}\left(T_{O}-T_{O}^{\mathrm{SCref}}\right),
$$

where $\mathrm{SHF}_{O}$ is the SHF received by the ocean in KEmod, $\mathrm{SHF}_{O}^{\text {SCref }}$ is the mean seasonal cycle of SHF in the KE simulation, $\alpha_{\mathrm{SWmod}}$ is the modified $\alpha_{\mathrm{SW}}, T_{o}$ is the SST in KE-mod, and $T_{O}^{\text {SCref }}$ is the mean seasonal cycle of SST in KE. The mean state and seasonal cycle of KEmod are very close to that of KE (not shown), as can be expected from the fact that the time integral of both SHF are equivalent. As seen in Fig. 1d, the standard deviation of SST in KE-mod has dramatically decreased and the Niño-3 average is now $0.4{ }^{\circ} \mathrm{C}$, a value close to that of TI. The total $\alpha$ in Niño-3 in KE-mod is now $-21 \mathrm{~W} \mathrm{~m}^{-2} \mathrm{C}^{-1}$, close to that of TI. This further confirms that the decrease of ENSO amplitude is largely due to the changes in $\alpha_{\mathrm{SW}}$.

In summary, the correct ENSO amplitude in KE is obtained from an error compensation: it results from a too weak dynamical positive feedback associated with a too weak heat flux negative feedback. In TI, the heat flux feedback is closer to that of the reanalysis, whereas the dynamical feedback stays too weak and results in a suppressed ENSO. The analysis presented here, in Hourdin et al. (2006), and in B07 further suggests that 
a) Shortwave $\alpha_{\text {sw }}$ (Niño 3)

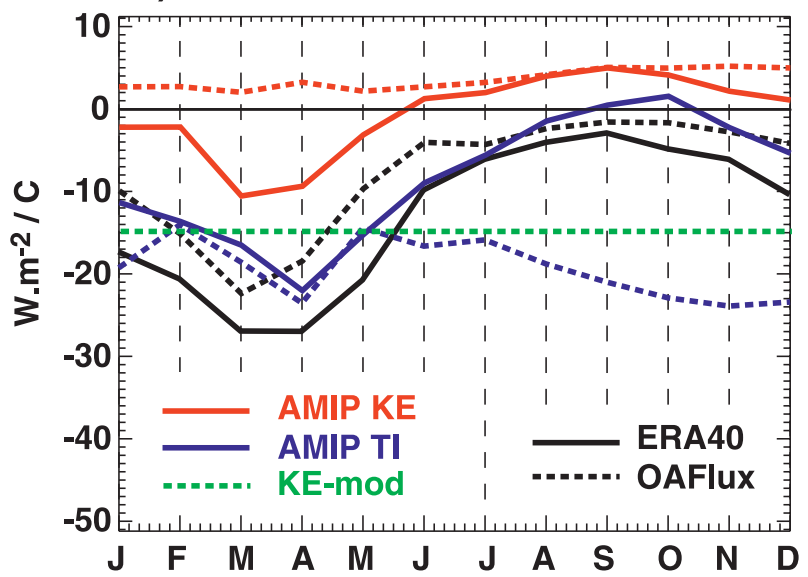

b) Latent $\alpha_{\mathrm{LH}}$ (Niño 3)

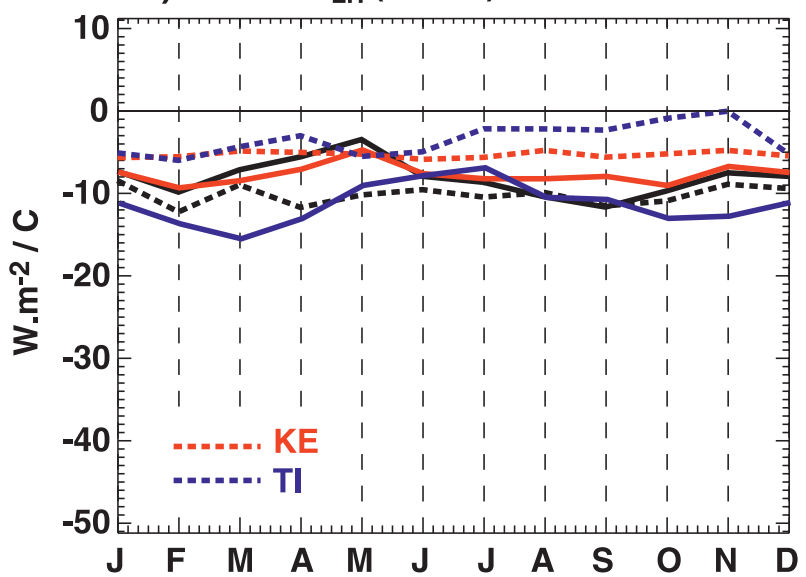

FIG. 12. Monthly evolution of (a) the shortwave component of $\alpha\left(\alpha_{\mathrm{SW}}\right)$ and (b) the LHF component of $\alpha\left(\alpha_{\mathrm{LH}}\right)$, curve colors as in Fig. 11b. The green dashed curve in (a) indicates the value of $\alpha_{\mathrm{SW}}$ used in the KE-mod sensitivity simulation (see text).

the "improved" $\alpha$ in AMIP-TI and TI is most likely due to, again, error compensation as the deep convection is much too strong and the cloud cover too extended when the Tiedke scheme is used.

\section{Radiative feedbacks over the cold tongue}

To further understand the change of $\alpha_{\mathrm{SW}}$ between AMIP-KE and AMIP-TI, the radiative feedbacks in the east equatorial Pacific are now analyzed in more detail during the ENSO amplification period (NH summerautumn), when TI exhibits the largest error in the Niño-3 $\alpha_{\mathrm{SW}}$ (Fig. 12a). A closer examination of maps of $\alpha_{\mathrm{SW}}$ for the ISCCP satellite observations during the JulyDecember period shows that the two regimes discussed in the introduction coexist in the Niño-3 region (Fig. 13b): a regime of negative $\alpha_{\mathrm{SW}}$ to the west, associated with deep convection, and a regime of positive $\alpha_{\mathrm{SW}}$ in the east Pacific, associated with the cold tongue/stratocumulus system. ERA-40 and ISCCP exhibit marked differences in this eastern region (Figs. 13a and 13b). Cronin et al. (2006) show that ERA-40, indeed, has a too strong surface cloud forcing in the ITCZ area when compared to in situ moorings observations, whereas ISCCP is broadly in agreement. The AMIP-KE simulation (Fig. 13c) has a structure closer to that of ISCCP, whereas AMIP-TI (Fig. 13d) has a structure closer to ERA-40, with too strong negative feedback over the ITCZ, and extending toward the equator (this may be due to the AGCM used in ERA-40 also having a Tiedke-type convection scheme). Nevertheless, the region of positive $\alpha_{\text {SW }}$ in AMIP-KE extends too far west and exhibits too strong values when compared to ISCCP. This explains the weaker negative feedback during ENSO amplification. In KE and TI (Figs. 13e and 13f), these biases are again amplified as the cold tongue regime (in KE) and the convective regime (in TI) take over the entire east Pacific all the way to the date line.

Next we look at the influence of the large-scale atmospheric circulation. A given SST can be associated with different regimes of vertical motions (Bony et al. 2004). It is therefore necessary to distinguish these regimes to further understand the origin of the weaker $\alpha_{\mathrm{SW}}$ in KE. The time evolution of the anomalous SHF, the vertical velocity at $500 \mathrm{hPa}\left(\omega_{500}\right)$, the SST anomaly, and the SST is shown for the far east Pacific $\left(5^{\circ} \mathrm{N}-5^{\circ} \mathrm{S}\right.$, $110^{\circ}-90^{\circ} \mathrm{W}$ ) for the El Niño composites in Fig. 14. The vertical velocity at $500 \mathrm{hPa}$ is a good proxy for large-scale deep convection $\left(\omega_{500}<0\right)$ and subsidence $\left(\omega_{500}>0\right)$ regimes (Bony et al. 2004; Bony and Dufresne 2005). In ISCCP, the increase in SHF during increasing SST (hence a positive $\alpha_{\mathrm{SW}}$ ) from July to December peaks at $15 \mathrm{~W} \mathrm{~m}^{-2}$ in September-October of year 0 (black solid curve in Fig. 14a). The SHF rapidly decreases to become a negative feedback as SST reaches the deep convection threshold in November-December. As evidenced by a $\omega_{500}$ on average $>20 \mathrm{hPa}$ day $^{-1}$, the positive $\alpha_{\text {Sw }}$ until October of year 0 , indeed, occurs in a predominantly subsident regime over the cold tongue (Fig. 13b; see also Bony and Dufresne 2005): when the SST increases, the stratocumulus deck is destabilized and the SHF increases. In AMIP-KE, the SHF anomaly reaches $30 \mathrm{~W} \mathrm{~m}^{-2}$ in December of year 0 (red solid curve in Fig. 14a) and its subsequent decrease lags that of ISCCP by about three months, allowing much more heat to enter the ocean mixed layer during this key El Niño amplification phase. In coupled mode (KE), as the cold tongue is too well developed, the deep convection regime is never reached in the east Pacific, even at the peak of El Niño ( $\omega_{500}$ stays positive; see Fig. 14b). 

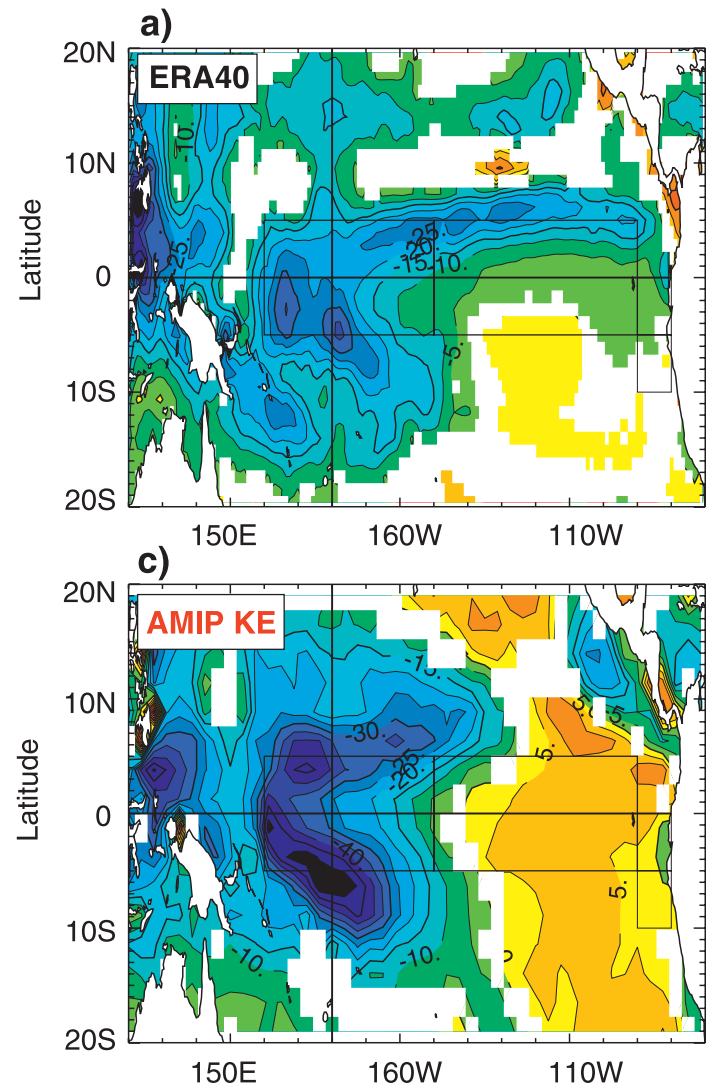

$20 S$

b)

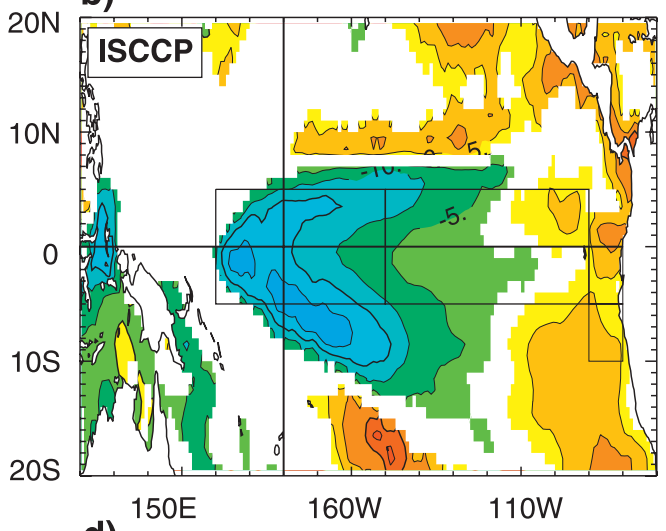

$20 \mathrm{~N}$

d)

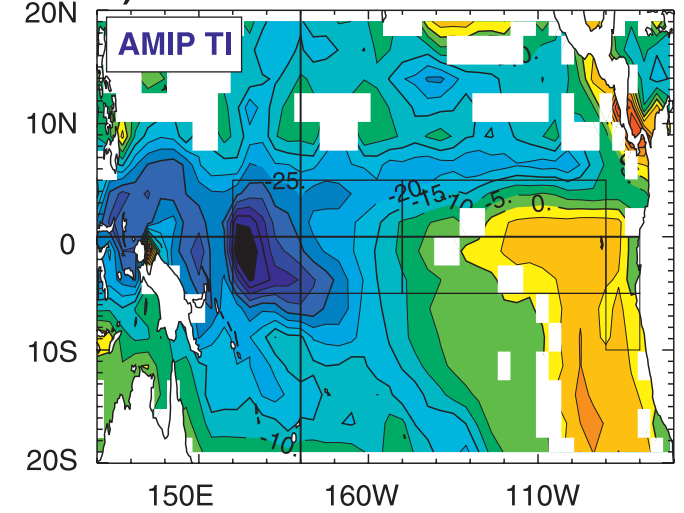

e)
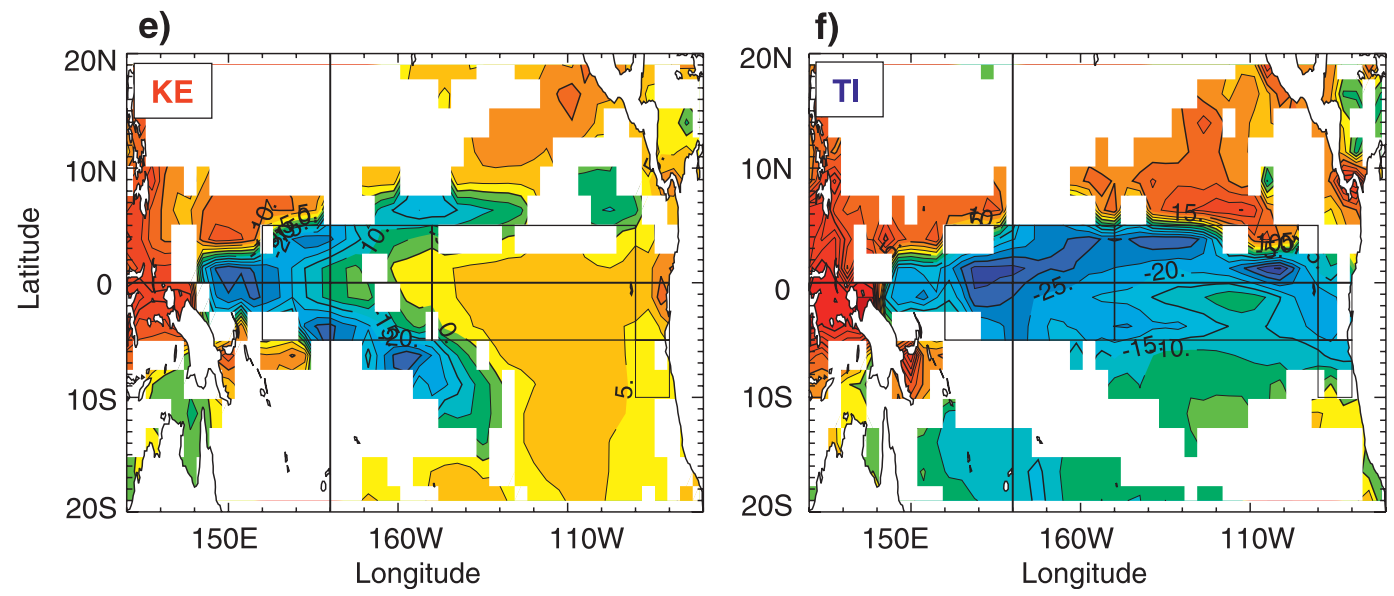

FIG. 13. Maps of $\alpha_{\mathrm{SW}}$, computed as the point-wise linear regression of $\mathrm{SHF}_{\text {anom }}=f\left(\mathrm{SST}_{\text {anom }}\right)$ for (a) ERA-40, (b) ISCCP/HadISST1.1, (c) AMIP-KE, (d) AMIP-TI, (e) KE, and (f) TI. Only correlations larger than 0.15 are shown. Contour interval is $5 \mathrm{~W} \mathrm{~m}^{-2} \mathrm{C}^{-1}$. The Niño-3 and Niño-4 boxes are added.

Consequently, $\alpha_{\mathrm{SW}}$ stays positive throughout the event (Fig. 14a), and even through the year (Fig. 12a). In sharp contrast, TI almost always exhibits a dominant deep convection regime in the far east Pacific (Figs. 14b), leading to the strongly negative $\alpha_{\mathrm{SW}}$ seen all year round (Fig. 12a). This difference between KE and TI was also noted by $\mathrm{B} 07$, who show that the largest difference of surface cloud forcing occurred in the subsidence regime, which includes the eastern part of the Pacific (B07, their Fig. 13).

Several studies have shown that deep convection was roughly occurring for SSTs higher than $26^{\circ}-27^{\circ} \mathrm{C}$ (Lau et al. 1997; Bony et al. 1997, 2004). To identify this threshold in the far east Pacific, $\omega_{500}$ is binned as a function of SST in Fig. 15. For ERA-40, the deep convection threshold is near $27.6^{\circ} \mathrm{C}$, a value usually not 
a) SHF anomaly $\left(\mathrm{W} \cdot \mathrm{m}^{-2}\right)$

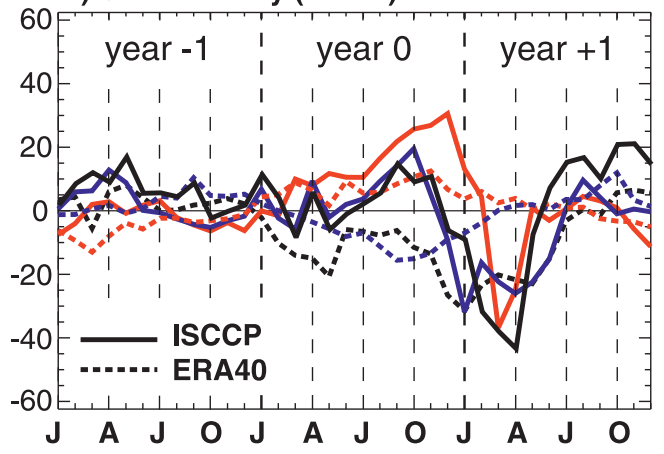

c) SST anomaly (C)

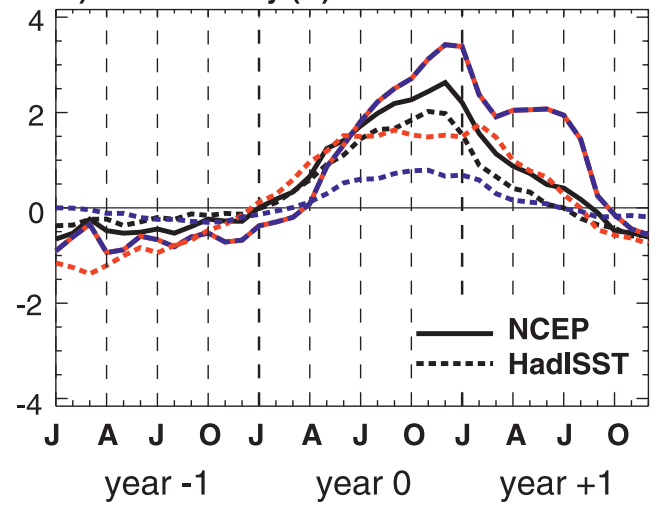

b) Vertical velocity at $500 \mathrm{hPa}(\mathrm{hPa} /$ day $)$

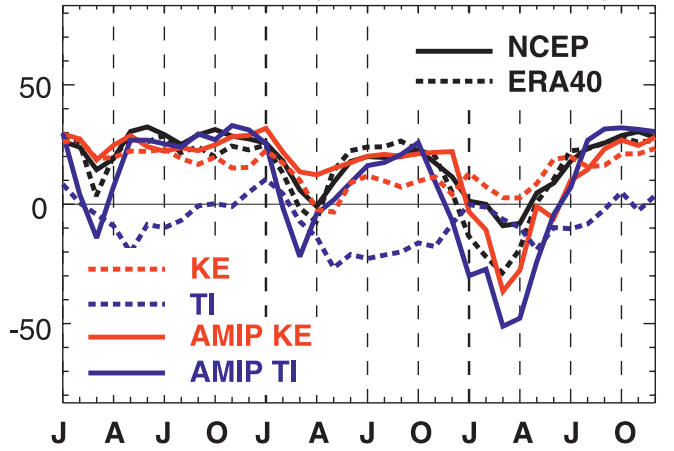

d) SST (C)

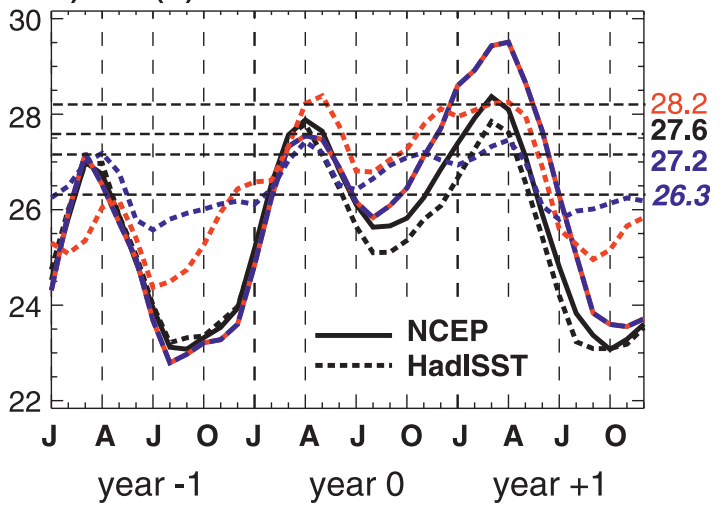

FIG. 14. El Niño composite evolution in the eastern Pacific $\left(5^{\circ} \mathrm{N}-5^{\circ} \mathrm{S}, 110^{\circ}-90^{\circ} \mathrm{W}\right)$, corresponding to the region of positive $\alpha_{\text {SW }}$ in Fig. 13b), of (a) SHF, (b) vertical velocity at $500 \mathrm{hPa}$, (c) SST anomalies, and (d) SST: ISCCP or NCEP (solid black), ERA-40 or HadISST1.1 (dashed black), AMIP-KE (solid red), AMIP-TI (solid blue), KE (dashed red), and TI (dashed blue). The convective thresholds derived from Fig. 15 are added in (d).

reached during the seasonal cycle in this region (Fig. 2a). AMIP-KE has a higher SST threshold $\left(28.2^{\circ} \mathrm{C}\right)$ than that of AMIP-TI $\left(27.2^{\circ} \mathrm{C}\right)$. This low value AMIP-TI explains the spurious $\mathrm{NH}$ spring incursion of convection in the east Pacific, noted in Fig. 2d. In coupled mode, KE maintains the $28.2^{\circ} \mathrm{C}$ threshold of AMIP-KE, whereas the deep convection threshold for TI becomes even lower (26. $3^{\circ} \mathrm{C}$, Fig. 15). When using these thresholds, in Fig. 14, one can readily explain the regime changes both in time and between the simulations and the observations. As seen from Fig. 14d, the two convective events in the ERA-40 composite (April of year 0 and January-May of year 1; Fig. 14b) correspond to times when the deep convection threshold $\left(27.6^{\circ} \mathrm{C}\right.$ in Fig. $\left.14 \mathrm{~d}\right)$ is reached. Similarly, the higher threshold for AMIP-KE when compared to AMIP-TI explains the longer subsidence regime for AMIP-KE (November-January) discussed above. Figure $14 \mathrm{~d}$ also clearly shows that convection cannot be reached during El Niño in KE because the SST almost never reaches $28.2^{\circ} \mathrm{C}$. Conversely, because of the very low threshold in TI, deep convection almost always occurs in the east Pacific in this simulation
(Fig. 2f). Such a low deep convection threshold provides a very effective mechanism to prevent the development of El Niño in this simulation.

\section{Summary and discussion}

The atmosphere feedbacks during ENSO in two coupled GCMs that differ only by the atmosphere convection parameterization used are analyzed. Using the Kerry-Emanuel scheme (KE), ENSO has about the right amplitude; however, this is shown to be due to an error compensation between a too weak Bjerknes feedback $(\mu)$ and a too weak heat flux feedback $(\alpha)$. Using the Tiedke scheme (TI), a too strong deep convection leads to a doubling of $\alpha$. Any SST anomaly in the east Pacific is therefore strongly damped and, since the Bjerknes feedback remains weak, ENSO is suppressed in TI. The mechanisms are unraveled by analyzing the atmosphereonly equivalent simulations (AMIP-KE and AMIP-TI).

The detailed analysis of the heat flux feedback in the east Pacific, where the damping of SST is key to ENSO evolution, shows that the shortwave heat flux (SHF) 


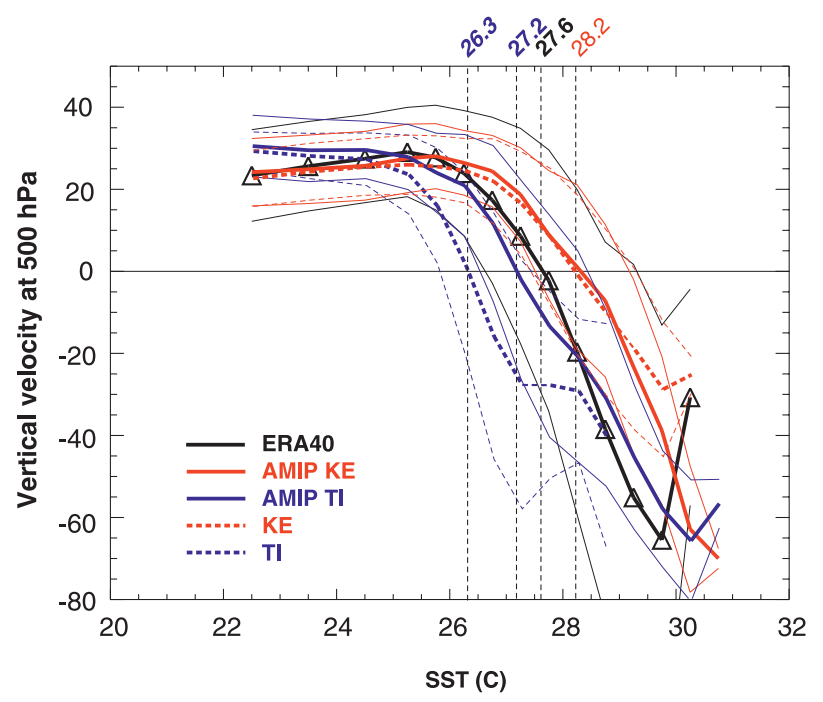

FIG. 15. Vertical velocity at $500 \mathrm{hPa}\left(\omega_{500}\right)$ binned as a function of SST in the eastern Pacific $\left(5^{\circ} \mathrm{N} / 5^{\circ} \mathrm{S}, 110^{\circ}-90^{\circ} \mathrm{W}\right)$ : ERA-40 (solid black), AMIP-KE (solid red), AMIP-TI (solid blue), KE (dashed red), and TI (dashed blue). The bins are indicated by black triangles on the ERA-40 curve. The convective threshold is defined for each curve as the limit between the subsidence regime $\left(\omega_{500}>0\right)$ and the convective regime $\left(\omega_{500}<0\right)$. The thin lines denote the \pm 1 std dev for each bin.

feedback $\alpha_{\mathrm{SW}}$ is the dominant term, especially during the ENSO amplification phase in NH summer and autumn. The SHF feedback is further analyzed as a blend of two different regimes, both influenced by the largescale circulation: the deep convection regime, where $\alpha_{\mathrm{SW}}$ is negative, and the subsidence/cold tongue/marine stratocumulus clouds regime, where $\alpha_{\mathrm{SW}}$ is positive (Fig. 13b). In AMIP-KE, the subsidence regime is too extended and explains the too weak absolute value of $\alpha_{\mathrm{SW}}$ in this simulation. In AMIP-TI, the deep convection regime is stronger and explains the increased absolute value of $\alpha_{\mathrm{SW}}$ (Fig. 12 and Figs. 13c,d). These different regime distributions can be traced back to different deep convection thresholds in the east Pacific $\left(28.2^{\circ} \mathrm{C}\right.$ versus $27.2^{\circ} \mathrm{C}$, Fig. 15). In $\mathrm{KE}$ and $\mathrm{TI}$ these biases are amplified as the subsidence regime (in KE) and the deep convection regime (in TI) take over the entire east Pacific. Interestingly, east of the date line, the structure of $\alpha_{\mathrm{SW}}$ for AMIP-TI is closer to that of the ERA-40 reanalysis (see also Hourdin et al. 2006), whereas the structure of $\alpha_{\mathrm{SW}}$ for AMIP-KE is closer to that of the ISCCP satellite observations (Fig. 13). As shown by Cronin et al. (2006), the ISCCP radiative feedbacks compare better with that of in situ observation than ERA-40, which has a too strong convection over the ITCZ, like AMIP-TI. Hence, the correct value for $\alpha_{\mathrm{SW}}$ in the TI physics is again due to an error compensation, this time between a too strong deep convection and a too weak subsidence regime- both associated with a too low SST deep convection threshold.

Many of these errors in KE and TI can be traced back to errors in the background state (Fig. 2), most of which are already present in the AMIP simulations, pointing to a predominantly atmosphere origin. The westward shift of the cold tongue/trade winds system in KE (already present in AMIP-KE) will enhance the regions of positive SHF feedback. The too strong deep convection in TI (and AMIP-TI) and a too warm SST in the east Pacific associated with a too low deep convection threshold will, on the other hand, enhance regions of negative SHF feedback. Interestingly, the mechanisms that lead to errors in the background state in TI-namely, a damping of the seasonal cycle (B07) -also operate at interannual time scales, that is, to damp ENSO. This gives hope that alleviating the background errors will also correct the interannual features of the model.

According to Hourdin et al. (2006), the marine stratocumulus cloud cover in AMIP-KE is much too weak (their Fig. 19). Deser et al. (1993) have shown that, if the background amount of low clouds is underestimated, the radiative response to changes in low-level subtropical cloudiness is overestimated. This agrees with the analysis presented in Fig. 14a, where $\alpha_{\mathrm{SW}}$ in AMIP-KE is more positive than that of ISCCP. Conversely, Hourdin et al. (2006) also show that AMIP-TI has more low-level clouds in the subtropics than AMIP-KE. This leads to a weaker positive $\alpha_{\mathrm{SW}}$ in the subsidence regime over the cold tongue region (Fig. 13d) and an overall stronger SHF damping in the east Pacific (Fig. 14a). These differences between TI and KE physics are most prominent when the cold tongue is present, that is, from June to October-a key amplification period for ENSO and a time when AMIP-TI exhibits severe biases (Fig. 2f). The underestimation of low-level subtropical cloudiness is a classical and persistent bias of coupled GCMs (Karlsson et al. 2008). This suggests that most models will overestimate the SHF feedback in the east Pacific during ENSO, leading to an overall weaker $\alpha$ in this region, as noted in many models (Sun et al. 2006, 2008; Philip and van Oldenborgh 2006; Lin 2007; Lloyd et al. 2009). Although the low clouds are a prime candidate to explain these SHF biases, high cirrus clouds could also contribute to $\alpha_{\mathrm{SW}}$ changes. A more detailed analysis will be required to fully conclude on this point.

The origin of the too weak Bjerknes feedback $(\mu)$ both in $\mathrm{KE}$ and TI is more challenging to track down and involves both local and nonlocal mechanisms. That the AMIP simulations have about the correct value for $\mu$ (Fig. 9) but that this value is divided by about two in the coupled simulation points to errors in the mean state, that is, changes in the mean SST gradients that drive the 
atmosphere circulation. Marti et al. (2009) show that, when the atmospheric meridional resolution is increased from $2.5^{\circ}$ to $1.8^{\circ}$ in $\mathrm{KE}, \mu$ is also increased from 4.6 (Fig. 9) to $6 \mathrm{~N} \mathrm{~m}^{-2} \mathrm{~K}^{-1}$. Besides improved internal dynamics, the fact that the atmosphere can better "see" the equatorial ocean waveguide $\left(2^{\circ} \mathrm{N}-2^{\circ} \mathrm{S}\right)$ and, hence, have a stronger dynamical response to the same SST anomaly can explain this result. Lin (2007) also argues that $\mu$ is a function of the background wind speed (since the zonal wind stress depends on it), which has errors in GCMs. In any case $\mu$ exhibits a large diversity among present models (Guilyardi 2006; Lloyd et al. 2009), and more work is needed to fully understand this diversity. These too low $\alpha$ and $\mu$ atmospheric feedbacks can explain both the too early decay of El Niño in KE (Fig. 4) and the shortlived upwelling in the seasonal cycle (Fig. 2e).

Several other studies explored the sensitivity of the ENSO amplitude to $\alpha$ and $\mu$. Battisti and Hirst (1989) showed that the amplitude of El Niño is anticorrelated with the intensity of $\alpha$. In their theoretical study and using a linear model, they estimated that the ENSO amplitude is divided by 5 if $\alpha$ doubles, a relation close to what is found between KE and TI. The weaker $\alpha$ in coupled models when compared to their equivalent AMIP configuration was also noted by Sun et al. (2008), who attribute it to a weakened precipitation response in the coupled mode. The results presented here suggest that this may also be associated to shortcomings in the representation of marine stratocumulus cloudiness and/ or the deep convection threshold.

Wu and Kirtman (2007) pointed out that AMIP-type simulations have shortcomings in the representation of air-sea interaction in regions and periods when the atmospheric forcing dominates over the SST forcing. This occurs mostly during the warm/rainy season in convective regimes and can explain the stronger $\alpha$ in AMIP-KE and AMIP-TI when compared to that of KE and TI. That the feedbacks are better represented in the coupled mode can also be seen from Fig. 13, where the structure of the KE and TI feedbacks are closer to that of ISCCP (the bow-shaped negative feedback surrounded by positive feedback), whereas the AMIP-KE and AMIP-TI feedback structures are closer to that of ERA-40, which is also based on a model forced by observed SSTs.

The coexistence of two regimes of opposite feedback sign for $\alpha_{\text {Sw }}$ possibly has implications for the response of ENSO to climate change. Higher SSTs can lead to more occurrence of the deep convection regime (provided that the SST deep convection threshold remains the same) and an overall stronger negative feedback, as shown by Philip and van Oldenborgh (2006) for several coupled models. Nevertheless, the other feedbacks rel- evant to ENSO (background state, ocean feedbacks, ...) will also evolve. In the models used for the IPCC AR4, the resulting balance of feedbacks is such that no clear trend in ENSO change is seen for the next century. As shown here, a systematic and detailed evaluation of atmospheric feedbacks during ENSO in the present-day climate simulations, for which observations are available for validation, is a necessary step to fully understand the ENSO simulation in coupled GCMs, and its likely change in the future. A first attempt to evaluate these atmospheric feedbacks in the CMIP3 models is presented in Lloyd et al. (2009).

Acknowledgments. Fruitful discussions with Pascale Delecluse, Julia Slingo, Matthieu Lengaigne, Sandrine Bony, David Neelin, Jean-Louis Dufresne, Fredéric Hourdin, Jérome Vialard, Claude Frankignoul, and JeanYves Grandpeix are gratefully acknowledged. This work was partly funded by the European Community ENSEMBLES (Grant GOCE-CT-2003-505539) and DYNAMITE (Grant 003903-GOCE) projects under the Sixth Framework Programme and by the CNRS PICS CORDIAL. EG is indebted to SOEST of the University of Hawaii for providing support for a research sabbatical during the course of this study. The OAFlux data were provided by WHOI (available online at http://oaflux.whoi. edu/data.html). CMAP merged precipitations were provided by NOAA/CDC (available online at http://www.cdc. noaa.gov/cdc/data.cmap.html). NCEP reanalysis-derived data was provided by the NOAA/OAR/ESRL PSD (available online at http://www.cdc.noaa.gov/). We thank Paul Berrisford for making the ECMWF reanalysis available at the University of Reading, via BADC and Jean-Marc Molines and Gurvan Madec for providing the ORCA05 simulations.

\section{REFERENCES}

AchutaRao, K., and K. Sperber, 2006: ENSO simulations in coupled ocean-atmosphere models: Are the current models better? Climate Dyn., 27, 1-16.

Barnier, B., and Coauthors, 2006: Impact of partial steps and momentum advection schemes in a global ocean circulation model at eddy-permitting resolution. Ocean Dyn., 56, 543-567.

Battisti, D. S., and A. C. Hirst, 1989: Interannual variability in the tropical atmosphere-ocean system: Influence of the basic state and ocean geometry. J. Atmos. Sci., 46, 1678-1712.

Bjerknes, J., 1969: Atmospheric teleconnections from the equatorial Pacific. Mon. Wea. Rev., 97, 163-172.

Bony, S., and K. A. Emanuel, 2001: A parameterization of the cloudiness associated with cumulus convection: Evaluation using TOGA COARE data. J. Atmos. Sci., 58, 3158-3183.

_, and J.-L. Dufresne, 2005: Marine boundary layer clouds at the heart of tropical cloud feedback uncertainties in climate models. Geophys. Res. Lett., 32, L20806, doi:10.1029/ 2005 GL023851. 
— K. Lau, and Y. C. Sud, 1997: Sea surface temperature and large-scale circulation influences on tropical greenhouse effect and cloud radiative forcing. J. Climate, 10, 2055-2077.

— , J. Dufresne, H. Le Treut, J. Morcrette, and C. Senior, 2004: On dynamic and thermodynamic components of cloud changes. Climate Dyn., 22, 71-86.

Braconnot, P., F. Hourdin, S. Bony, J. Dufresne, J. Grandpeix, and O. Marti, 2007: Impact of different convective cloud schemes on the simulation of the tropical seasonal cycle in a coupled ocean-atmosphere model. Climate Dyn., 29, 501-520.

Burgers, G., and G. J. van Oldenborgh, 2003: On the impact of local feedbacks in the central Pacific on the ENSO cycle. J. Climate, 16, 2396-2407.

Capotondi, A., A. Wittenberg, and S. Masina, 2006: Spatial and temporal structure of Tropical Pacific interannual variability in 20th century coupled simulations. Ocean Modell., 15, 274.

Chelton, D. B., and Coauthors, 2001: Observations of coupling between surface wind stress and sea surface temperature in the eastern tropical Pacific. J. Climate, 14, 1479-1498.

Covey, C., and Coauthors, 2000: The seasonal cycle in coupled ocean-atmosphere general circulation models. Climate Dyn., 16, 775-787.

Cronin, M. F., N. A. Bond, C. W. Fairall, and R. A. Weller, 2006 : Surface cloud forcing in the east Pacific stratus deck/cold tongue/ITCZ complex. J. Climate, 19, 392-409.

Deser, C., S. Wahl, and J. J. Bates, 1993: The influence of sea surface temperature gradients on stratiform cloudiness along the equatorial front in the Pacific Ocean. J. Climate, 6, 1172-1180.

Dewitte, B., C. Cibot, C. Périgaud, S.-I. An, and L. Terray, 2007 Interaction between near-annual and ENSO modes in a CGCM simulation: Role of equatorial background mean state. J. Climate, 20, 1035-1052.

Emanuel, K. A., 1994: Atmospheric Convection. Oxford University Press, $580 \mathrm{pp}$.

Fedorov, A. V., 2007: Net energy dissipation rates in the tropical ocean and ENSO dynamics. J. Climate, 20, 1108-1117.

_ ocean-atmosphere interactions: Bridging measurements and theory for El Niño. J. Climate, 14, 3086-3101.

Frankignoul, C., E. Kestenare, M. Botzet, A. Carril, H. Drange, A. Pardaens, L. Terray, and R. Sutton, 2004: An intercomparison between the surface heat flux feedback in five coupled models, COADS and the NCEP reanalysis. Climate Dyn., 22, 373-388.

Fu, R., A. D. Del Genio, and W. B. Rossow, 1994: Influence of ocean surface conditions on atmospheric vertical thermodynamic structure and deep convection. J. Climate, 7, 1092-1108.

Gill, A. E., 1980: Some simple solutions for heat-induced tropical circulation. Quart. J. Roy. Meteor. Soc., 106, 447-462.

Griffies, S. M., and Coauthors, 2009: Coordinated Ocean-ice Reference Experiments (COREs). Ocean Modell., 26, 1-46, doi:10.1016/j.ocemod.2008.08.007.

Guilyardi, E., 2006: El Niño-mean state-seasonal cycle interactions in a multi-model ensemble. Climate Dyn., 26, 329-348.

_ - and Coauthors, 2004: Representing El Niño in coupled ocean-atmosphere GCMs: The dominant role of the atmospheric component. J. Climate, 17, 4623-4629.

- A. Wittenberg, A. Fedorov, M. Collins, C. Wang, A. Capotondi, G. J. van Oldenborgh, and T. Stockdale, 2009: Understanding El Niño in ocean-atmosphere general circulation models: Progress and challenges. Bull. Amer. Meteor. Soc., 90, 325-340.
Hourdin, F., and Coauthors, 2006: The LMDZ4 general circulation model: Climate performance and sensitivity to parametrized physics with emphasis on tropical convection. Climate Dyn., 27, 787-813.

Jin, F.-F., 1997: An equatorial ocean recharge paradigm for ENSO. Part I: Conceptual model. J. Atmos. Sci., 54, 811-829.

— S. T. Kim, and L. Bejarano, 2006: A coupled-stability index for ENSO. Geophys. Res. Lett., 33, L23708, doi:10.1029/ 2006GL027221.

Kalnay, E., and Coauthors, 1996: The NCEP/NCAR 40-Year Reanalysis Project. Bull. Amer. Meteor. Soc., 77, 437-470.

Karlsson, J., G. Svensson, and H. Rodhe, 2008: Cloud radiative forcing of subtropical low level clouds in global models. Climate Dyn., 30, 779-788.

Kim, D., J.-S. Kug, I.-S. Kang, F.-F. Jin, and A. T. Wittenberg, 2008: Tropical Pacific impacts of convective momentum transport in the SNU coupled GCM. Climate Dyn., 31, 213-226.

Klein, S. A., and D. L. Hartmann, 1993: The seasonal cycle of low stratiform clouds. J. Climate, 6, 1587-1606.

Lau, K. M., H. T. Wu, and S. Bony, 1997: The role of large-scale atmospheric circulation in the relationship between tropical convection and sea surface temperature. J. Climate, 10, 381-392.

Lengaigne, M., and G. Vecchi, 2009: Contrasting the termination of moderate and extreme El Niño events in coupled general circulation models. Climate Dyn., in press.

—, E. Guilyardi, J.-P. Boulanger, C. Menkes, P. Inness, P. Delecluse, and J. M. Slingo, 2004: Triggering of El Niño by westerly wind events in a coupled general circulation model. Climate Dyn., 23, 601-620.

Li, T., 1997a: Air-sea interactions of relevance to the ITCZ: Analysis of coupled instabilities and experiments in a hybrid coupled GCM. J. Atmos. Sci., 54, 134-147.

, 1997b: Phase transition of the El Niño-Southern Oscillation: A stationary SST mode. J. Atmos. Sci., 54, 2872-2887. , and S. G. H. Philander, 1996: On the annual cycle of the equatorial eastern Pacific. J. Climate, 9, 2986-2998.

, and T. F. Hogan, 1999: The role of the annual mean climate on seasonal and interannual variability of the tropical Pacific in a coupled GCM. J. Climate, 12, 780-792.

Lin, J.-L., 2007: The double-ITCZ problem in IPCC AR4 coupled GCMs: Ocean-atmosphere feedback analysis. J. Climate, 20, 4497-4525.

Lloyd, J., E. Guilyardi, H. Weller, and J. Slingo, 2009: The role of atmosphere feedbacks during ENSO in the CMIP3 models. Atmos. Sci. Lett., in press.

Madec, G., P. Delecluse, M. Imbart, and C. Lévy, 1998: OPA 8.1 ocean general circulation model reference manual. L'Institut Pierre-Simon Laplace Tech. Note 11, 94 pp.

Marti, O., and Coauthors, 2009: Key features of the IPSL ocean atmosphere model and its sensitivity to atmospheric resolution. Clim. Dyn., in press.

McPhaden, M. J., S. E. Zebiak, and M. H. Glantz, 2006: ENSO as an integrating concept in earth science. Science, 314, 1740-1745.

Meehl, G. A., and Coauthors, 2007: Global climate projections. Climate Change 2007: The Physical Science Basis, S. D. Solomon et al., Eds., Cambridge University Press, 747-846.

Menkes, C., J. Boulanger, A. Busalacchi, J. Vialard, P. Delecluse, M. McPhaden, and N. Grima, 1998: Impact of TAO vs. ERS wind stresses onto simulations of the tropical Pacific Ocean during the 1993-1998 period by the OPA OGCM. Climatic impact of scale interaction for the tropical ocean- atmosphere system, Euroclivar Workshop Rep. 13, 46-48. 
Molines, J. M., B. Barnier, T. Penduff, L. Brodeau, A. M. Treguier, S. Theetten, and G. Madec, 2006: Definition of the global $1 / 2^{\circ}$ experiment with CORE interannual forcing, ORCA05-G50. LEGI Rep. DRA-1-11-2006, 34 pp.

Neale, R. B., J. H. Richter, and M. Jochum, 2008: The impact of convection on ENSO: From a delayed oscillator to a series of events. J. Climate, 21, 5904-5924.

Neelin, J. D., and H. A. Dijkstra, 1995: Ocean-atmosphere interaction and the tropical climatology. Part I: The dangers of flux correction. J. Climate, 8, 1325-1342.

Norris, J. R., and C. B. Leovy, 1994: Interannual variability in stratiform cloudiness and sea surface temperature. J. Climate, 7, 1915-1925.

Philip, S., and G. J. van Oldenborgh, 2006: Shifts in ENSO coupling processes under global warming. Geophys. Res. Lett., 33, L11704, doi:10.1029/2006GL026196.

Ramanathan, V., and W. Collins, 1991: Thermodynamic regulation of ocean warming by cirrus clouds deduced from observations of the 1987 El Niño. Nature, 351, 27-32.

Rayner, N., D. Parker, E. Horton, C. Folland, L. Alexander, D. Rowell, E. C. Kent, and A. Kaplan, 2003: Global analyses of sea surface temperature, sea ice, and night marine air temperature since the late nineteenth century. J. Geophys. Res., 108, 4407, doi:10.1029/2002JD002670.

Reynolds, R. W., 1988: A real-time global sea surface temperature analysis. J. Climate, 1, 75-86.

Rossow, W. B., and R. A. Schiffer, 1991: ISCCP cloud data products. Bull. Amer. Meteor. Soc., 72, 2-22.

Schneider, E. K., 2002: Understanding differences between the equatorial Pacific as simulated by two coupled GCMs. J. Climate, 15, 449-469.

Solomon, S. D., D. Qin, M. Manning, M. Marquis, K. Averyt, M. M. B. Tignor, H. L. Miller Jr., and Z. Chen, Eds., 2007: Climate Change 2007: The Physical Science Basis. Cambridge University Press, 996 pp.

Stephens, G. L., 2005: Cloud feedbacks in the climate system: A critical review. J. Climate, 18, 237-273.

Sun, D.-Z., and Coauthors, 2006: Radiative and dynamical feedbacks over the equatorial cold tongue: Results from nine atmospheric GCMs. J. Climate, 19, 4059-4074.

_- Y. Yu, and T. Zhang, 2008: Tropical water vapor and cloud feedbacks in climate models: A further assessment using coupled simulations. J. Climate, 22, 1287-1304.

Trenberth, K. E., and D. P. Stepaniak, 2001: Indices of El Niño evolution. J. Climate, 14, 1697-1701.

Uppala, S. M., and Coauthors, 2005: The ERA-40 Re-Analysis. Quart. J. Roy. Meteor. Soc., 131, 2961-3012.

Valcke, S., L. Terray, and A. Piacentini, 2000: Oasis 2.4, Ocean atmosphere sea ice soil: User's guide. CERFACS Tech. Rep. TR/CMGC/00-10, 85 pp. van Oldenborgh, G. J., S. Philip, and M. Collins, 2005: El Niño in a changing climate: A multi-model study. Ocean Sci., 1, 81-95.

Waliser, D. E., B. Blanke, J. D. Neelin, and C. Gautier, 1994: Shortwave feedbacks and El Niño-Southern Oscillation: Forced ocean and coupled ocean-atmosphere experiments. J. Geophys. Res., 99, 25 109-25 125.

Wallace, J. M., T. P. Mitchell, and C. Deser, 1989: The influence of sea surface temperature on surface wind in the eastern equatorial Pacific: Seasonal and interannual variability. J. Climate, 2, 1492-1499.

Wang, B., and Q. Ding, 2008: Global monsoon: Dominant mode of annual variation in the tropics. Dyn. Atmos. Oceans, 44, $165-183$.

Wang, C., and J. Picaut, 2004: Understanding ENSO physics-A review. Earth's Climate: The Ocean-Atmosphere Interaction, Geophys. Monogr., Vol. 147, Amer. Geophys. Union, 21-48.

Wittenberg, A. T., A. Rosati, N.-C. Lau, and J. J. Ploshay, 2006: GFDL's CM2 global coupled climate models. Part III: Tropical Pacific climate and ENSO. J. Climate, 19, 698-722.

Wu, Q., D. J. Karoly, and G. R. North, 2008: Role of water vapor feedback on the amplitude of season cycle in the global mean surface air temperature. Geophys. Res. Lett., 35, L08711, doi:10.1029/2008GL033454.

Wu, R., and B. P. Kirtman, 2007: Regimes of seasonal air-sea interaction and implications for performance of forced simulations. Climate Dyn., 29, 393-410.

Wu, X., L. Deng, X. Song, G. Vettoretti, W. R. Peltier, and G. J. Zhang, 2007: Impact of a modified convective scheme on the Madden-Julian Oscillation and El Niño-Southern Oscillation in a coupled climate model. Geophys. Res. Lett., 34, L16823, doi:10.1029/2007GL030637.

Xie, P., and P. A. Arkin, 1997: Global precipitation: A 17-year monthly analysis based on gauge observations, satellite estimates, and numerical model outputs. Bull. Amer. Meteor. Soc., 78, 2539-2558.

Yu, L., and R. A. Weller, 2007: Objectively analyzed air-sea heat fluxes for the global ice-free oceans (1981-2005). Bull. Amer. Meteor. Soc., 88, 527-539.

Zhang, G. J., and N. A. McFarlane, 1995: Role of convective scale momentum transport in climate simulation. J. Geophys. Res., 100 (D1), 1417-1426.

Zhang, X., and M. J. McPhaden, 2008: Eastern equatorial Pacific forcing of ENSO sea surface temperature anomalies. J. Climate, 21, 6070-6079.

Zhang, Y., W. B. Rossow, A. A. Lacis, V. Oinas, and M. I. Mishchenko, 2004: Calculation of radiative fluxes from the surface to top of atmosphere based on ISCCP and other global data sets: Refinements of the radiative transfer model and the input data. J. Geophys. Res., 109, D19105, doi:10.1029/ 2003JD004457. 